\title{
A novel animal model for testing the in vivo potency of putative local anesthetic compounds
}

\author{
Ph.D. Thesis \\ Árpád Sáfrány-Fárk DMD
}

Supervisor: Gyöngyi Horváth, MD, DSc

Theoretical Medicine Doctoral School

University of Szeged

Albert Szent-Györgyi Medical and Pharmaceutical Centre

Faculty of Medicine

Department of Physiology

2018

Szeged 


\section{Publications}

\section{Full papers related to the Thesis}

I. Safrany-Fark A., Petrovszki Z., Kekesi G., Liszli P., Benedek G., Keresztes C., Horvath G. In vivo potency of different ligands on voltage-gated sodium channels. Eur J Pharmacol. 2015, 762:158-64.

II. Tuboly G., Tar L., Bohar Z., Safrany-Fark A., Petrovszki Z., Kekesi G., Vecsei L., Pardutz A., Horvath G. The inimitable kynurenic acid: the roles of different ionotropic receptors in the action of kynurenic acid at a spinal level. Brain Res Bull. 2015, 112:52-60.

\section{Full papers not involved in the Thesis}

Safrany-Fark A., Petrovszki Z., Kekesi G., Keresztes C., Benedek G., Horvath G. Telemetry monitoring for non-invasive assessment of changes in core temperature after spinal drug administration in freely moving rats. J Pharmacol Toxicol Methods. 2015, 72:19-25.

\section{Abstracts}

Safrany-Fark A., Petrovszki Z., Kekesi G., Liszli P., Benedek G., Nagy K., Horvath G. Motor nerve sensitivity changes caused by $\mathrm{N}$-arachidonoyl-dopamine and capsaicin in rats. XIVth Conference of the Hungarian Neuroscience Society, Budapest, January 17-19, 2013

Horvath G., Safrany-Fark A., Petrovszki Z., Kekesi G., Benedek G. Thermoregulatory and motor disturbances after intrathecal injections in freely moving rats. IBRO International Workshop, Szeged, January 16-17, 2014

Pinke I., Safrany-Fark A., Daubner B., Segatto E. Detection of positional disorders of maxillary first molars in cleft palate patients. 8th International Orthodontic Congress, WFO London, September 27-30, 2015

Safrany-Fark A., Segatto E., Voros L., Pinke I. Analysis of transversal and sagittal dental cast measurements in cleft and control patients. 8th International Orthodontic Congress, WFO London, September 27-30, 2015 
Safrany-Fark A., Harsanyi R., Kenyeres K., Pinke I. Determination of survival rate of primary molars in control population, and assessment of the dental age for cleft and control groups. 8th International Orthodontic Congress, WFO London, September 27-30, 2015 
1. Introduction

\section{Contents}

1.1. Pain

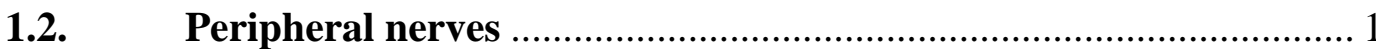

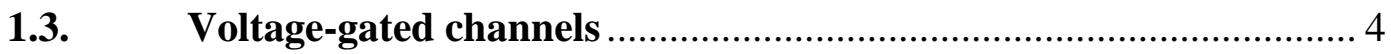

1.3.1. Voltage-gated sodium channels .................................................... 4

1.3.2. Voltage-gated potassium channels .................................................. 7

1.4. Ligands acting on voltage-gated sodium channels ….................... 9

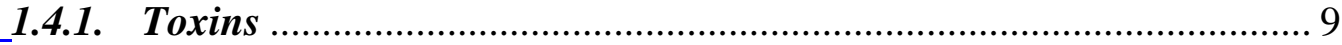

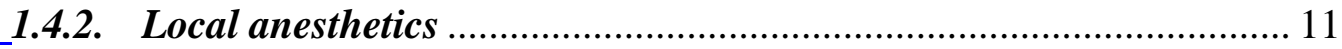

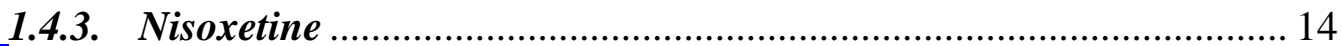

1.4.4. Capsaicin, arachidonic acid and arachidonoyl ethanolamide ......... 14

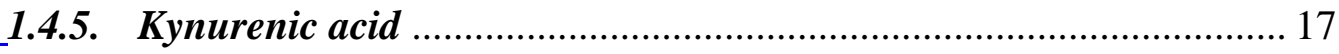

1.5. Methodological background ...................................................... 18

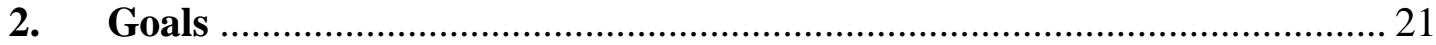

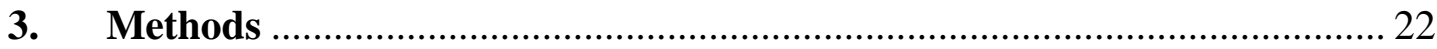

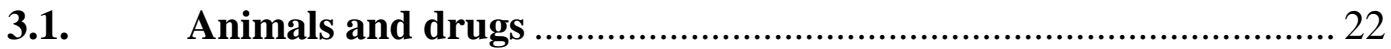

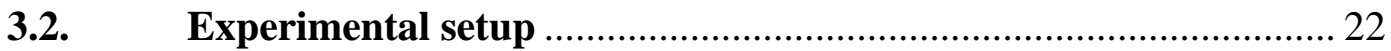

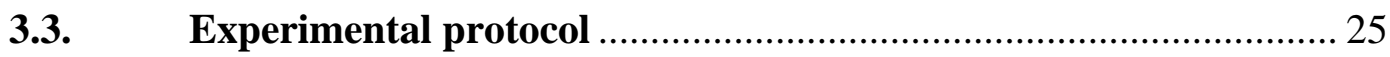

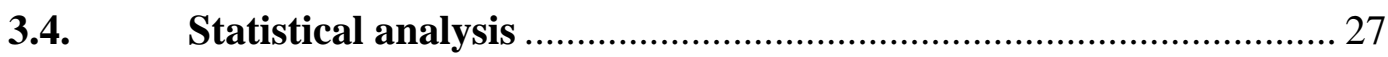

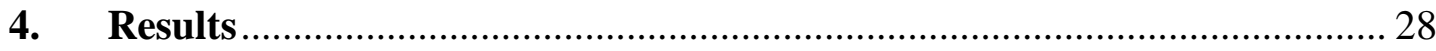

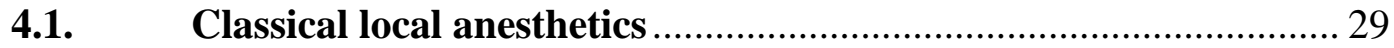

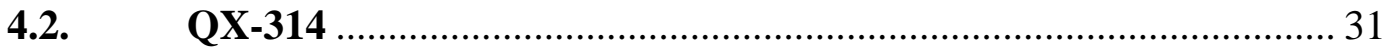

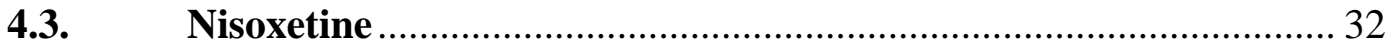

4.4. Capsaicin, arachidonic acid and arachidonoyl ethanolamide ....... 33

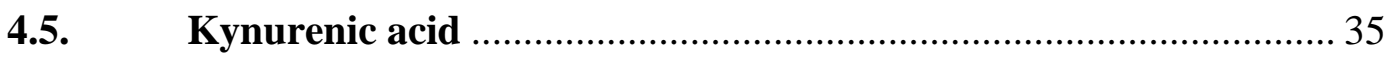

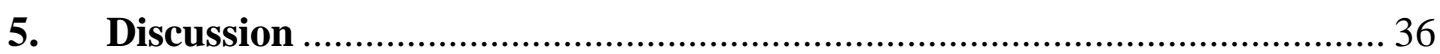

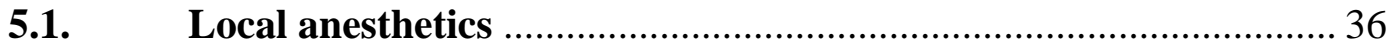

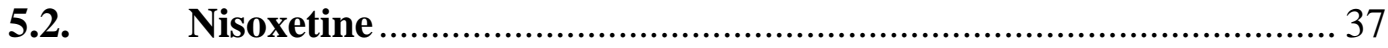

5.3. Capsaicin, arachidonic acid and arachidonoyl ethanolamide ....... 38

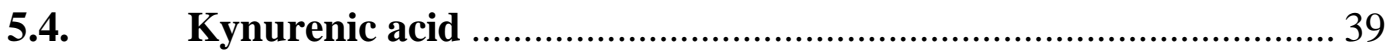

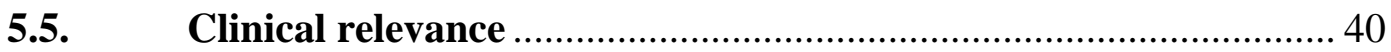

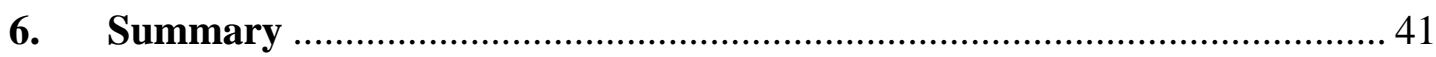




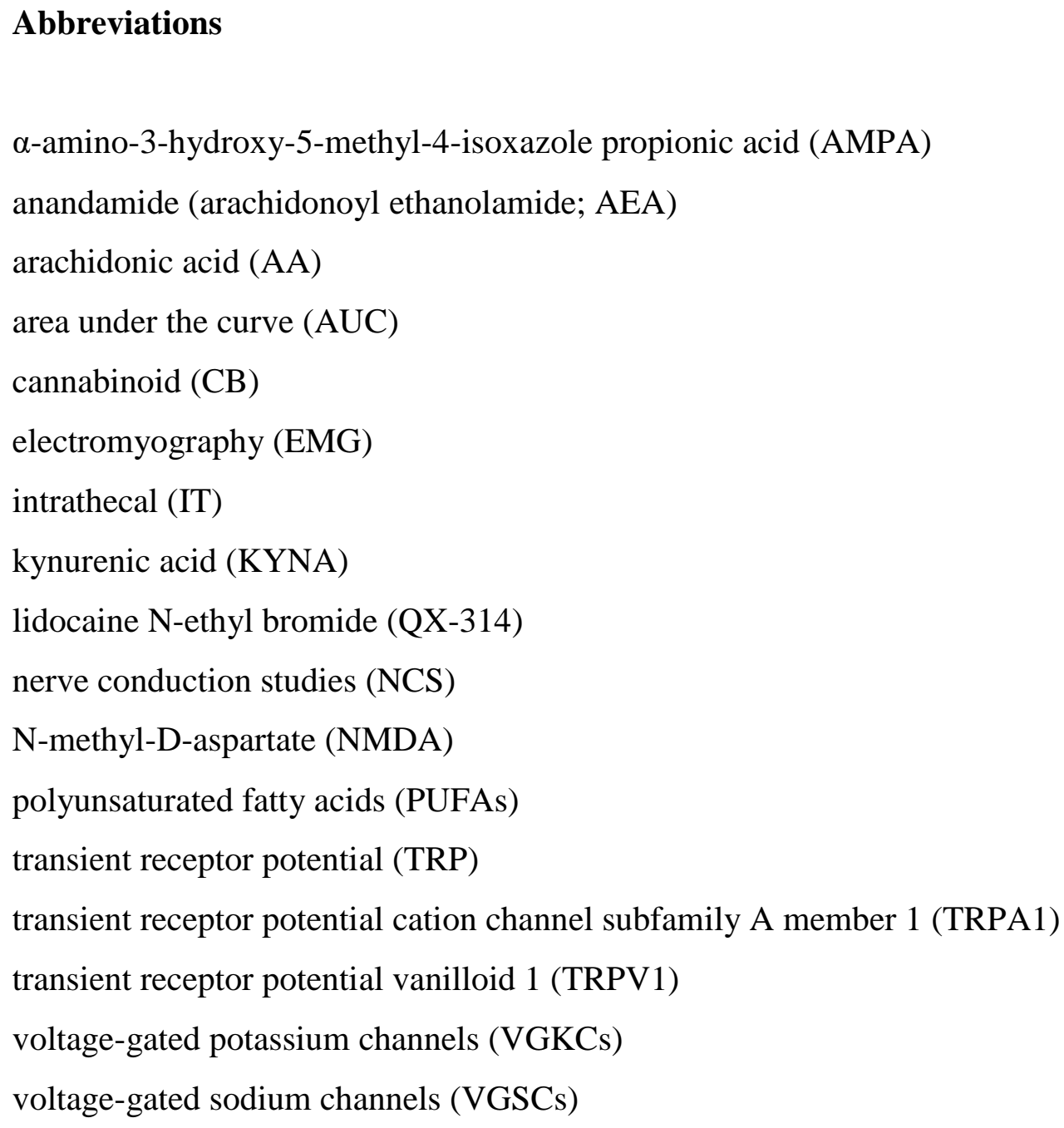




\section{Introduction}

\subsection{Pain}

Pain is an unpleasant sensory and emotional experience associated with actual or potential tissue damage, or described in terms of such damage (Aminoff et al., 2006). "Nociception" is the sensory nervous system's response to certain harmful or potentially harmful stimuli. The nociceptive system is functioning as a warning system; therefore, it has a threshold that is low enough for it to be activated before actual damage has occurred. Analgesic technologies and current postoperative pain management are primarily based on nonsteroidal anti-inflammatory drugs, opioids or local anesthetics. Thus, they can be administrated systemically for central medication, or regionally (epidural, topical and infiltrative analgesia) for local anesthesia (Chrubasik et al., 1993). The use of local anesthesia during surgical procedures became prominent during the past decade. Additionally, local anesthetics are also applied to ameliorate unpleasant sensations associated with other procedures, such as tracheal intubation. Acute pain, accompanying dental manipulations, can also be avoided with the application of these drugs (Strichartz, 1987). Beside the pain relief, these drugs have a considerable effect on the motor function as well. The action mechanism of the local anesthetics is the inhibition of the axonal activities by the reduction or total blockade of action potentials. The primary sites of their actions are the voltage gated sodium channels (VGSCs), which are transmembrane proteins essential for the influx of sodium ions that subserve impulse generation and propagation in nerve and muscle cells (Strichartz, 1987).

\subsection{Peripheral nerves}

In the peripheral nervous system wide variety of axons can be found with different size and conductivity. These axons have different physiological properties, function and possible drug targeting sites. Thus, sensory and motor axons have different hyperpolarization characteristics, refractoriness, super- and subexcitability in the recovery cycle, and they contain VGSCs in different percentage (Krishnan et al., 2009). Biophysical and functional differences between these axons might have some impact on their inhibitory capabilities, too. To describe and identify different axonal types classification systems were developed at the beginning of the 
past century. Erlanger \& Gasser (1937) classified vertebrate nerve fibers by their conduction velocities, and divided them into three groups, from A to C (Table 1) (Aidley, 1998). Group A has been subdivided into four subgroups from $\mathrm{A} \alpha$ to $\mathrm{A} \delta$. An alternative classification system describes sensory axons by their diameter, containing groups from I to IV (Table 1) (Lloyd, 1943; Hunt, 1954). Still nowadays, these systems have important role as guidelines to understand the structure of the peripheral nervous system. However, deeper and detailed understanding of the occurrence of specific receptors and channels on different axon types were required to identify the molecular targeting sites for selective drug effects.

\begin{tabular}{ccccl} 
Type & Group & $\begin{array}{c}\text { Diameter } \\
(\boldsymbol{\mu m})\end{array}$ & $\begin{array}{c}\text { Conduction } \\
\text { velocity } \\
\left(\mathbf{m s}^{-1}\right)\end{array}$ & \\
& & & Function \\
\hline $\mathrm{A} \alpha$ & & $15-20$ & $50-120$ & Motor fibres to skeletal muscle \\
$\mathrm{A} \alpha$ & Ia & $15-20$ & $70-120$ & Primary endings on muscle spindles \\
$\mathrm{A} \alpha$ & Ib & $12-20$ & $70-120$ & Golgi tendon organ afferents \\
$\mathrm{A} \beta$ & II & $5-10$ & $30-70$ & Secondary endings on muscle \\
& & & & spindles, touch, pressure \\
$\mathrm{A} \gamma$ & & $3-6$ & $15-30$ & Motor innervation of muscle spindles \\
$\mathrm{A} \delta$ & III & $2-5$ & $5-25$ & Pressure/pain receptors \\
$\mathrm{B}$ & & 3 & $3-15$ & Autonomic preganglionic \\
$\mathrm{C}$ & & $0.5-1$ & $0.5-2$ & Autonomic postganglionic (non- \\
& & & & myelinated) \\
$\mathrm{C}$ & IV & $0.5-1$ & $0.5-2$ & Pain (non-myelinated)
\end{tabular}

Table 1. Classifications of mammalian nerve fibres (Aidley, 1998).

The axons of many neurons are myelinated (Figure 1.). The glial Schwann cells are responsible for the myelin formation in the peripheral nervous system. They acquire a protein-lipid complex coverage by wrapping their membrane around the axon up to 100 times, forming a sheath of myelin and providing an electrically insulating layer. The thickness of this myelin contributes to the diameter of the axon fiber and defines its conduction velocity. This myelin 
sheath fully covers the axon except at its ending and at the nodes of Ranvier (Figure 1. B). The size of the nodes is $1 \mu \mathrm{m}$ about $1 \mathrm{~mm}$ apart. However, C-fibers are simply surrounded by Schwann cells without forming a complete myelin sheath (Barrett et al., 2016).

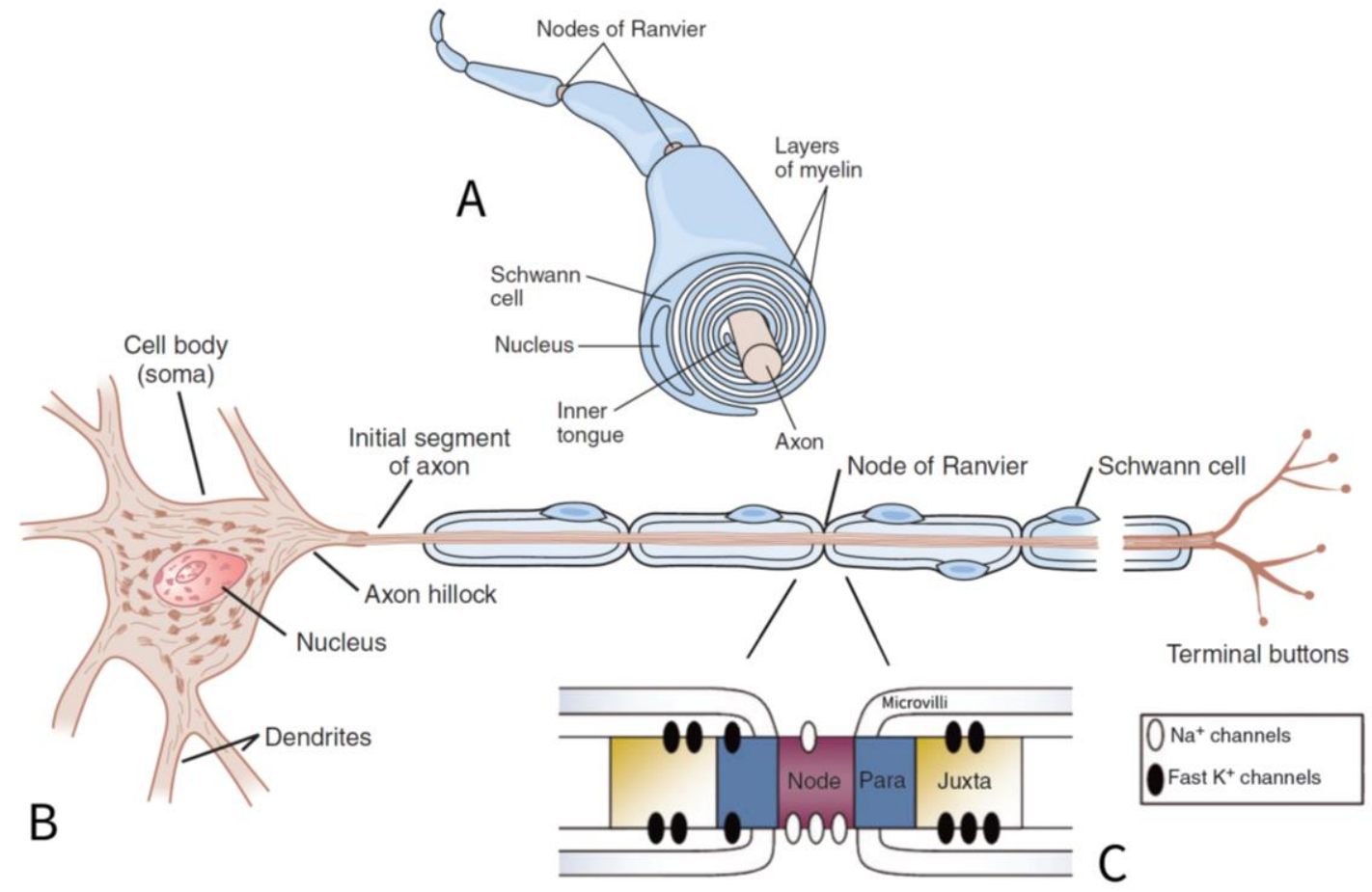

Figure 1. Schematic structure of the axons and the nodes of Ranvier (Barrett et al., 2016; Park et al., 2011)

Efficient and rapid propagation of action potentials (saltatory) depends on the molecular specialization of the nodes of Ranvier, what can be described as a unique set of ion channels, cell-adhesion molecules and cytoplasmic adaptor proteins. The node of Ranvier is organized into several distinct domains (nodal, paranodal and juxtaparanodal; Figure 1. C). VGSCs are concentrated at the nodal region, which generate the spike, and mediate the fast saltatory conduction that is thought to be the typical conduction pattern of myelinated axons (Poliak et al., 2003; Salzer, 2002). However, recent molecular anatomy studies showed that VGSCs are clustered on lipid rafts in C-fibers, resembling the channel organization of the nodes of Ranvier, causing a micro-saltatory conduction fashion along the axon (Neishabouri et al., 2014). The voltage-gated potassium channels (VGKCs) are clustered separately at the juxtaparanodal 
region and contribute to the repolarization during action potential. A specialized axoglial contact is formed between the axon and the myelinating cell at the paranodes (Poliak et al., 2003).

Some types of peripheral nerves contain several ligand binding sites along the axonal region (e.g. interleukin-6 receptor, $\gamma$-aminobutyric acid receptor, protease-activated receptor 1 , transient receptor potential vanilloid 1 (TRPV1) and insulin receptors) providing a way to influence their function (Corell et al., 2015; Lara-Ramírez et al., 2008; Shavit et al., 2018; Sugimoto et al., 2000). These receptors are present primarily on C-type sensory axons and less expressed on motor nerves. Therefore, motor nerves might be more predictable model for the investigation of the effects of different ligands acting on voltage gated channels.

\subsection{Voltage-gated channels}

Channel proteins allow ions to cross the membrane bilayer. The movement of these charged ions, such as sodium, potassium, calcium, or chloride, through these channels allows them to produce electrical signals (Hall et al., 2016; Ruben, 2014; Strichartz, 1987). Many of the channels are selective for one or more specific ions, which is due to their different structural characteristics, such as diameter, shape, electrical properties and chemical bonds along its intracellular domains. The controlled ion permeability of the channels is provided by different gating mechanisms. Protein channels opened by binding of a chemical substance (ligand) are named as "ligand-gated channels". Other impacts, such as heat or mechanical deformation, can also activate specific (thermo- or mechanosensitive) channels. Voltage-gated ion channels have a charged or dipolar moiety, which translates or rotates during potential changes (Hall et al., 2016; Ruben, 2014; Strichartz, 1987). Voltage-gated ion channels are pore-forming molecules in the lipid bilayer of most cells, which open in response to alterations in the cell's transmembrane electrical potential (Elinder et al., 2017).

\subsubsection{Voltage-gated sodium channels}

VGSCs in the excitable cell membrane allow movement of the sodium ions across the bilayer. They initiate the action potential in most of the excitable tissues such as neurons, cardiac and skeletal muscle fibers. As suggested by their name, the activity of these channels is regulated by the voltage difference across the membrane they span. The kinetics of VGSCs were 
described by Hodgkin and Huxley in squid axon in 1952 and were part of their subsequent model (Ruben, 2014; Hodgkin et al., 1952\}.

VGSCs have large alpha- and small beta-subunits (Figure 2. A) (Ruben, 2014). The alphasubunit is a single protein with 24 transmembrane segments arranged in four domains (Figure 2. B), the S5 and S6 segments of each domain and the S5-S6 linkers form a central pore (Ruben, 2014; Catterall et al., 2007). The transmembrane electric field, provided by positively charged residues in the S4 segments, is responsible for the voltage sensitivity of the sodium channels. The beta-subunits modulate the channel, but the alpha-subunit alone is sufficient to conduct sodium (Ruben, 2014).

The membrane potential change alters the conformation of the channel proteins, regulating their opening and closing (Strichartz, 1987). At the resting potential (- $70 /-90 \mathrm{mV})$ the channels are in closed states, while upon depolarization they change to an open state, causing ionconduction, which inactivates them into a non-conducting state. A rapid increase in the sodium current, caused by the fast activation of the channels, is followed by a slower decline. The inactivation of sodium channels is not the reversal of the activation, rather it converts channels to a temporary state that is responsible for the absolute refractory period. This inactivated state is slowly converted back to the closed, resting form when the membrane becomes repolarized (Strichartz, 1987). 

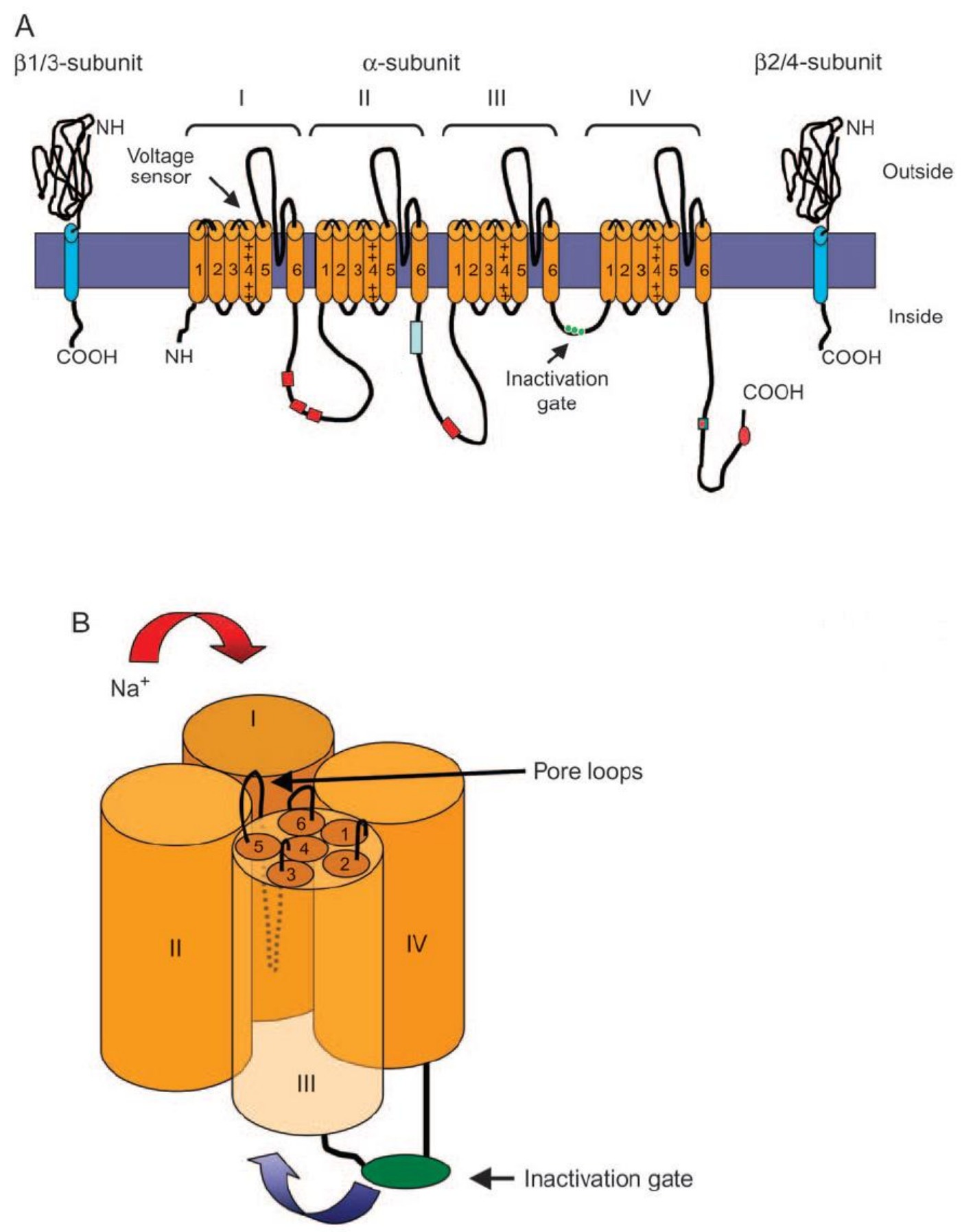

Figure 2. The primary sequence of the voltage-gated sodium channel (A) and the threedimensional arrangement of the alpha-subunit (B) (Cusdin et al., 2008) 
Two distinct gene families encode $9 \alpha$ subunit paralogs (SCNXA genes) and $5 \beta$ subunits (SCNXB genes). The proteins coded by the SCNXA genes are named from NaV1.1 to NaV1.9; those which coded by SCNXB genes, are named $\beta 1-4$ (a $\beta 1 \mathrm{~B}$ is included too). The expression of different sodium channel isoforms is tissue-specific. NaV1.5 is the primary variant in cardiac muscle, and $\mathrm{NaV} 1.4$ is in skeletal muscle. $\mathrm{NaV} 1.1, \mathrm{NaV} 1.2$ and $\mathrm{NaV} 1.3$ are expressed primarily in the central, and $\mathrm{NaV} 1.7, \mathrm{NaV} 1.8, \mathrm{NaV} 1.9$ in the peripheral nervous system (Ruben, 2014). Nav1.6 can be found both peripherally and centrally, and it is the predominant channel subtype in nodes of Ranvier in the peripheral nervous system (Bucher et al., 2011; Krishnan et al., 2009). The specific localization of the different subtypes might provide a tool for selective modification of these channels by different ligands.

\subsubsection{Voltage-gated potassium channels}

Potassium channels also have a tetrameric structure with four identical protein subunits around the central pore (Figure 3. A, B). There are pore loops, which work as a narrow selectivity filter on the intracellular domains of the channel. During the resting state, the closed channels prevent potassium ions from passing to the extracellular space. When the membrane potential rises, the voltage change causes a conformational opening and allows an increased outward potassium diffusion through the channel. However, because of a slight delay, they open just at the same time when the sodium channels are beginning to close because of their inactivation. The decrease of sodium entry, and the simultaneous increase of potassium outflow from the cell speed up the repolarization process, and leads to a full recovery of the resting membrane potential (Hall et al., 2016). In 1992 Armstrong and his colleagues described the inactivation of voltage-gated potassium channels as a 'ball-and-chain' model in which inactivation is produced by a mobile part of the channel protein, which swings into the inner mouth of the open channel pore and blocks it (Figure 3. C) (Aidley, 1998). 
A

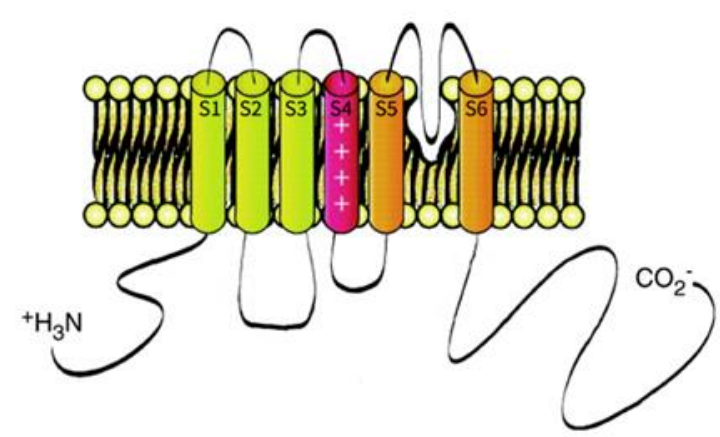

B

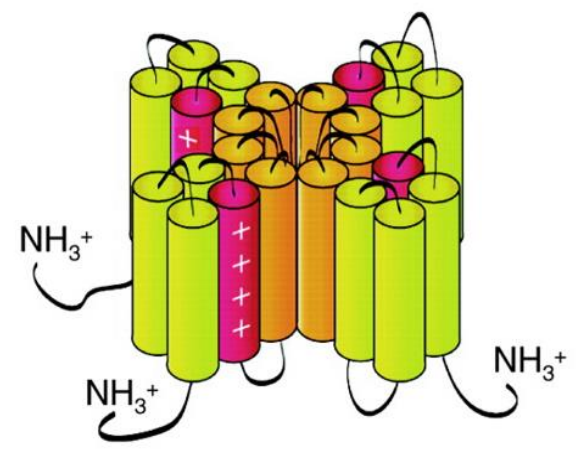

C

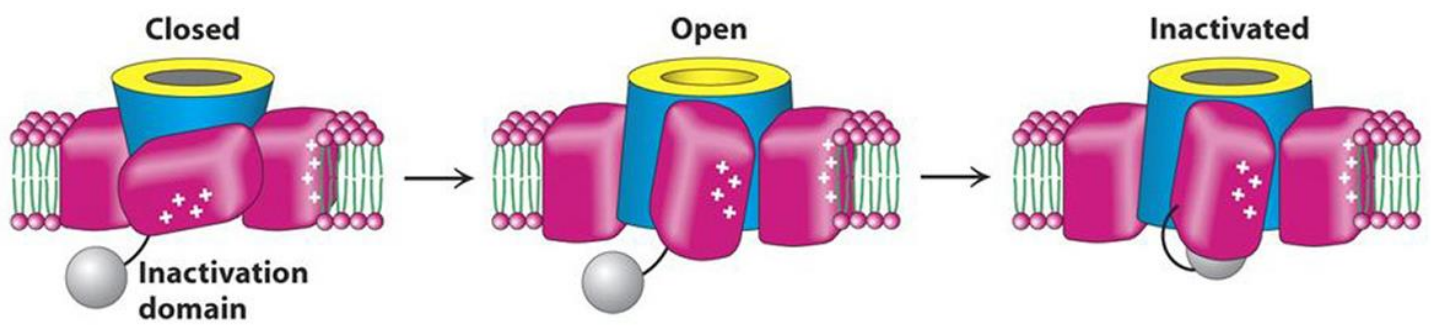

Figure 3. Schematic view of different structural domains of the voltage-gated potassium channels (A,B), and the illustration of 'ball-and-chain' model $(C)$ (Nerbonne et al., 2005)

The most diverse group of ion channels are $\mathrm{K}^{+}$channels. They are structurally divided into three major classes: (1) one pore domain Shaker-related channels with six transmembrane segments comprising voltage-gated $\mathrm{K}^{+}$channels $(\mathrm{Kv})$; (2) one pore domain inward rectifiers $\mathrm{K}^{+}$channels with two transmembrane segments (Kir); (3) and two pore domains with four transmembrane segments (the largest structural class). A wide variety of $\mathrm{K}^{+}$channels are involved in modulation of excitability of different neurones (Zagorodnyuk et al., 2002).

Several ligands can modify the action of these, or subtypes of these channels. The relatively non-selective blocker of VGKC, 4-aminopyridine, inactivates most of the subtypes (ArancibiaCarcamo et al., 2014; Zagorodnyuk et al., 2002). Many other ligands also affect $\mathrm{K}^{+}$channel action and selective influence of the different types is also possible. Charybdotoxin for example can inhibit some VGKCs as well as $\mathrm{Ca}^{2+}$-dependent $\mathrm{K}^{+}$channels. Selective large conductance $\mathrm{K}^{+}$channel blocker iberiotoxin and selective small conductance $\mathrm{K}^{+}$channel blocker apamin are 
also well known agents (Zagorodnyuk et al., 2002). The potential clinical importance of ligands such as $\alpha$-dendrotoxin and Phrixotoxin 2 is relevant (Wang et al., 2015; Yunoki et al., 2014). $\alpha$-Dendrotoxin is selective blocker of the low-threshold sustained Kv1 channels (they regulate subthreshold events: resting membrane potential, subthreshold oscillations, action potential threshold, membrane excitability and firing patterns) and a potential therapeutic candidate for the treatment of painful diabetic neuropathy. Phrixotoxin 2, acts on C-fibres, exhibits voltageindependent inhibition of the $\mathrm{K}^{+}$currents in some subpopulations of dorsal root ganglion cells. These channels contribute to the action potential repolarization differently in the axons of specific afferent pathways, therefore, they can help to find suitable selective molecular targets for termination of hyperexcitability and chronic pain (Arancibia-Carcamo et al., 2014). However classical nerve conduction inhibition is more likely to be caused by the VGSC effect of the different ligands than VGKC effects.

\subsection{Ligands acting on voltage-gated sodium channels}

A wide variety of chemical substances can alter the VGSC function. The best known groups of them are toxins and classical local anesthetics. However, a number of different other ligands with diverse chemical properties can also have significant effect on these channels.

\subsubsection{Toxins}

VGSCs are targets for a wide range of potent neurotoxins (Catterall et al., 2007) (Figure 4.). The central ion-conducting pore can be blocked at the extracellular side, binding to the outer mouth in a region known as site 1. These are named as pore-blocking toxins, and they completely terminate ion conduction in single channels (Ruben, 2014; Catterall et al., 2007). Neurotoxin receptor site 1 can be occupied by two different groups of toxins: the water soluble heterocyclic guanidines, such as tetrodotoxin (it is produced by symbiotic bacteria species of several aquatic animal) and saxitoxin (known from shellfish, but produced by several bacteria and flagellates too), and the peptidic $\mu$-conotoxins (isolated from cone snail) (Catterall et al., 2007).

Lipid-soluble grayanotoxins (found in rhododendron and other plants of the family Ericaceae) and alkaloids e.g. veratridine (from the family of Liliaceae), acotinine (from the plant Acotinum napellus) and batrachotoxin (from the skin of the Colombian frog Phyllobates aurotaenia) bind 
to receptor site 2 , preferentially during the activated state of the channel, leading to the block of sodium channel inactivation.

Neurotoxin receptor site 3 of VGSCs is occupied by several groups of polypeptide toxins, like $\alpha$-scorpion toxins, sea-anemone toxins and some spider toxins, thereby delaying or completely blocking sodium channel's inactivation, resulting in strong stimulation.

Neurotoxin receptor site 4 may be occupied by the $\beta$-scorpion toxins. They induce a shift in the voltage dependence of the channel activation in the hyperpolarizing direction, and reduces the peak sodium current amplitude.

The lipid-soluble brevetoxin and ciguatoxin (originating from the dinoflagellates Karenia brevis and Gambierdicus toxicus, respectively) enhance activity of these channels by binding to neurotoxin receptor site 5 causing a shift in the activation to more negative membrane potential and a block of inactivation similarly to the toxins targeting receptor site 2 (Catterall et al., 2007). All of these toxins alter the excitability of nerves and muscles, but they can also cause death in large doses, thus, the clinical relevance of their perineural application is strongly limited.

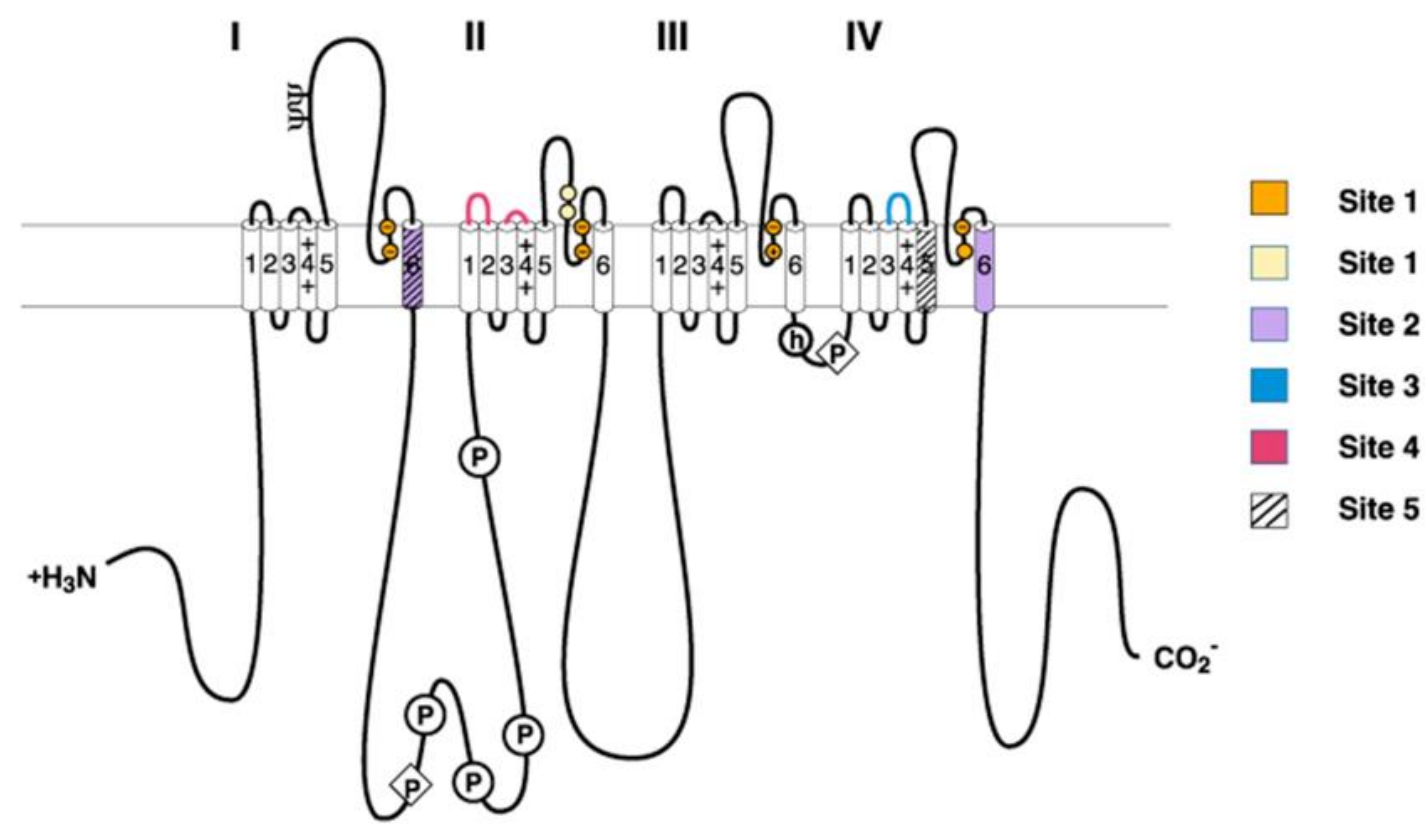

Figure 4. Neurotoxin receptor binding sites on voltage-gated sodium channels are illustrated by different colours (Catterall et al., 2007) 


\subsubsection{Local anesthetics}

The modification of sodium channel's activity is a major issue in pharmacology, as it was discussed above, these channels are targets for a variety of small molecules and peptides. Several classes of ligands act by blocking ion conduction through the channel's central pore (Ruben, 2014). Some of these molecules are drugs, producing reversible inhibition of nerve conduction when applied to the peripheral nerve fibers. In addition to inhibition of pain processing, they produce numbness due to blocking sensory, motor and autonomic nerve functions (Butterworth et al., 1990).

The first clinical application of cocaine to induce local anesthesia took place in Vienna, in 1884 by Koller (Ruben, 2014). The local anesthetics in clinical use are tertiary amines (with the exception of the neutral compound benzocaine) (Butterworth et al., 2009; Frazier et al., 1970). Lidocaine (2-(diethylamino)-N-(2,6-dimethylphenyl)acetamide; Figure 5. A), bupivacaine (1butyl-N-(2,6-dimethylphenyl)-monohydrochloride, monohydrate; Figure 5. B) and ropivacaine $((2 S)-N$-(2,6-dimethylphenyl)-1-propylpiperidine-2-carboxamide; Figure 5. C) are the most widely used ones (Nakagawa et al., 2013). These drugs, under physiological conditions, exist in a mixture of protonated and neutral, uncharged forms (Table 2.) (Butterworth et al., 2009; Frazier et al., 1970). The uncharged hydrophobic form can penetrate through the lipid layers of the neuronal cell membrane (Frazier et al., 1970).

Guarded receptor hypothesis suggests that local anesthetics can only access their binding site if the channel gate is open. Meanwhile, the modulated receptor hypothesis explains the state dependence of their binding by a different model: local anesthetic binding stabilizes the opened or inactivated states, which in turn binds local anesthetics with higher affinity than resting closed states (Ruben, 2014). Once they access to the local anesthetic binding site on the cytoplasmic side of the conducting pore of the VSCGs, the protonated form appears to be more potent than the neutral one (Butterworth et al., 1990; Frazier et al., 1970). Then amino acid residues create a three-dimensional drug receptor site in the inner surface of the S6 segments, thus they completely block ion conduction through the pore (Ruben, 2014; Catterall et al., 2015). 
A<smiles>CCN(CC)CC(=O)Nc1c(C)cccc1C</smiles>

C<smiles>CCCN1CCCC[C@H]1C(=O)Nc1c(C)cccc1C</smiles>

B<smiles>CCCCN1CCCCC1C(=O)Nc1c(C)cccc1C</smiles>

D<smiles>CC[N+](CC)(CC)CC(=O)Nc1c(C)cccc1C</smiles>

Figure 5. Chemical formula of lidocaine $(A)$, bupivacaine (B), ropivacaine $(C)$ and $Q X-314$ (D).

\begin{tabular}{lccc} 
Drug & $\mathbf{Q}_{7.4}$ & $\boldsymbol{P}^{\mathbf{0}}$ & $\boldsymbol{P}^{+}$ \\
\hline Ropivacaine & 115 & 775 & 0.46 \\
Bupivacaine & 346 & 2565 & 1.5 \\
Lidocaine & 43 & 310 & 0.061 \\
QX-314 & 0.306 & (no exist) & 0.306
\end{tabular}

Table 2. The octanol:buffer distribution coefficient (Q7.4), the octanol:buffer partition coefficient of the neutral (PO)and protonated $(\mathrm{P}+)$ drugs $\left(\mathrm{pH} 7.4\right.$ and $\left.25^{\circ} \mathrm{C}\right)($ Strichartz et al., 1990; Taheri et al., 2003). 
The axon types have different susceptibility to local anesthetics. Gasser and Erlanger have found that cocaine reduces the compound action potential of slower-conducting (smaller diameter) fibers more rapidly than those of faster-conducting (larger) fibers (Gasser et al., 1929), however, it seems that most of the commonly used local anesthetics do not follow this pattern (Gokin et al., 2001; Jaffe et al., 1996; Nakamura et al., 2003). The block of all sensory, motor and autonomic fibers may be acceptable in some settings, such as during surgery, but there are many clinical situations where a selective inhibition of some but not other axons would be desirable. One notable example of this is in labor analgesia, where the selective sensory blockade would allow the parturient to push effectively without feeling pain (Roberson et al., 2011; Sagie et al., 2010). There are recent reports of local anesthetic formulations with varying degrees of sensory selectivity, albeit of relatively brief duration. Block of nociceptors to produce analgesia without a loss of proprioception, motor or autonomic function may help early mobilization of patients following knee or hip joint replacement. Therefore sensory-selective local anesthesia has long been a key goal in drug development (Binshtok et al., 2007; Courtney, 1975; Roberson et al., 2011; Sagie et al., 2010; Starmer et al., 1986).

Strichartz firstly described in 1973 that the hydrophilic quaternary lidocaine derivative lidocaine N-ethyl bromide (QX-314) (Figure 5. D) is incapable of diffusion through the membrane lipid bilayer of myelinated nerve fibers (Strichartz, 1973). Subsequently, it was shown that QX-314 could enter into the cytoplasm through activated TRPV1 channels (e.g., induced by capsaicin) leading to the preferential block of VGSCs in nociceptors producing a selective antinociception (Binshtok et al., 2007; Kim et al., 2010; Lim et al., 2007). Furthermore, QX-314 seems to be able to interact with local anesthetics enhancing their effect on sensory and motor functions applied to the mixed, perisciatic nerve (Binshtok et al., 2009; Brenneis et al., 2014; Roberson et al., 2011). However, in mixed nerves the motor responses can be influenced by actions on sensory fibers, at least indirectly, through reflex arches. It should be mentioned that besides the classical local anesthetics, several other drugs could also influence VGSCs (Catterall et al., 2015). Thus, different sodium channel blockers inhibit action potential generation in the depolarized and rapidly firing cells that are responsible for pain, epilepsy, and arrhythmia without complete block of action potential generation in normally functioning cells. Some antiepileptic drugs (e.g. diphenylhydantoin, carbamazepine, and lamotrigine) prevent seizures in the brain; some antiarrhythmic drugs (such as quinidine 
and flecainide) interrupt and prevent cardiac arrhythmias by blocking cardiac sodium channels. Their higher doses cause major unwanted side effects, including complete loss of sensation in sensory nerves, sedation, coma or cardiac arrest in the heart (Catterall et al., 2015).

\subsubsection{Nisoxetine}

Nisoxetine ((RS)-3-(2-methoxyphenoxy)-N-methyl-3-phenylpropan-1-amine), Figure 6.) is a drug used in the therapy of affective disorders as a potent norepinephrine reuptake inhibitor (Yokogawa et al., 2002). It also suppresses the nicotine-evoked increase of hippocampal noradrenaline release by influencing the function of nicotinic acetylcholine receptors. Some data suggest that nisoxetine also induces an inhibition of the VGSCs in vitro circumstances (Chen et al., 2012; Hennings et al., 1999; Leung et al., 2013). The structure of nisoxetine and local anesthetics share important moieties, namely, a lipophilic structure at one end and an amine at the other, thus, it is not entirely unexpected that nisoxetine blocks VGSCs (Leung et al., 2013). Thus a recent study found that nisoxetine has a local anesthetic effect after infiltrative cutaneous administration that might be related to its VGSC blocking potency (Chen et al., 2012). Nisoxetine also produced dose-dependent spinal (central) anesthesia with a partially sensory-selective action over motor blockade (Leung et al., 2013).<smiles>CNCCC(Oc1ccccc1OC)c1ccccc1</smiles>

Figure 6. Chemical formula of nisoxetine

\subsubsection{Capsaicin, arachidonic acid and arachidonoyl ethanolamide}

Capsaicin (8-methyl- $N$-vanillyl-6-nonenamide, Figure 7. A) is a well-known vanilloid substance. It is the pungent agent in hot chili peppers, and perhaps one of the most enigmatic molecules ever produced by plants. It evokes a sharp burning pain sensation in contact with 
mucous membranes of mammals (Jancso et al., 1990; Jancso et al., 1968; Nagy et al., 2004). Capsaicin and other vanilloids (e.g. the resiniferatoxin found in Euphorbia resinifera) selectively and specifically activates the peptidergic non-myelinated, pain sensitive subpopulation of primary sensory fibers, leading to the pain sensation (Jancso et al., 1983; Porszasz et al., 1959). Capsaicin-sensitivity is quickly reduced following its large dose exposure, and it produces long-lasting regional, thermal and chemical analgesia without affecting non-nociceptive sensory, autonomic and motor nerves (Jancso et al., 1983; Porszasz et al., 1959). Capsaicin causes these effects through actions on transient receptor potential cation channel subfamily V member 1 (TRPV1) receptors found on nociceptive afferents, leading to the disturbance of the cellular trafficking of specific molecules. Binding studies showed that the TRPV1 receptors localize not only in the peripheral and central terminals of these fibers, but the perineural treatment with vanilloid compounds also cause inhibition of evoked action potentials (Jancso et al., 1983; Szallasi, 1994). Analgesia develops within hours, however nerve degeneration appears only several weeks after treatment (Mutoh et al., 2000; Oszlacs et al., 2015; Sann et al., 1995), suggesting that the TRPV1 receptors can be found on the other part of axons.

Some in vitro data proved that capsaicin can also influence the activity of VGSCs (Cao et al., 2007; Duan et al., 2007; Lundbaek et al., 2005). Furthermore, the application of capsaicin on mixed nerves caused a temporary inhibition of the compound action potentials (Petsche et al., 1983; Pettorossi et al., 1994). It also prolonged the tetrodotoxin-evoked motor impairment (Kohane et al., 1999). In these cases, it cannot be excluded that the disturbed sensory function influenced the motor performances, but nerves, contain only motor fibers, may avoid any indirectly evoked secondary responses.

Other lipid soluble ligands, polyunsaturated fatty acids (PUFAs) e.g. arachidonic acid (AA; Figure 7. C), and their derivatives also may have significant effect on VGSCs. Anandamide (arachidonoil-etanolamide: AEA; Figure 7. B), an AA derivative, is an endogenous ligand of cannabinoid (CB) and TRPV1 receptors (Di Marzo et al., 2000; Mechoulam et al., 1995). Thus, AEA activates the TRPV1 receptors leading to similar effects as were detected after capsaicin administration, however $\mathrm{CB} 1$ receptor activation also contribute to the effects of AEA administration (Dux et al., 2016). Functional studies suggest that CB receptors can be found in the sensory fibers but not in motor ones; therefore, the effects of these ligands on sensory 
neurons may be the sum of the changes in the activity of these different systems (Weller et al., 2011). Some in vitro data showed that both AA and AEA can inhibit the VGSCs' activity, but in vivo data are not available in this respect (Al Kury et al., 2014; Boland et al., 2008; Duan et al., 2008; Hong et al., 2004; Lee et al., 2002; Nicholson et al., 2003).

The effects of PUFAs on voltage-gated ion channels was recently summarized (Elinder et al., 2017). $\mathrm{Na}^{+}$and $\mathrm{Ca}^{++}$channels are generally inhibited by PUFAs, which changes their conductance and opening kinetics. In contrast VGKCs, which are less affected by steady-state inactivation at resting potential, are typically activated by them. PUFAs can also either increase or decrease conductance at positive voltages. In many cases, both mechanisms are involved. The opening kinetics are sometimes faster and the closing kinetics slower in the presence of PUFAs. There are also results showing that PUFAs induce an acceleration of channel inactivation. Hydrophobic interaction between fatty acids and VGSC can be an important action mechanism that develops much faster after intracellular application, suggesting an intracellular site of action. However, some other studies did not find any difference between their intra- or extracellular application (Elinder et al., 2017).

A<smiles>COc1cc(CNC(=O)CCCC/C=C/C(C)C)ccc1O</smiles>

B

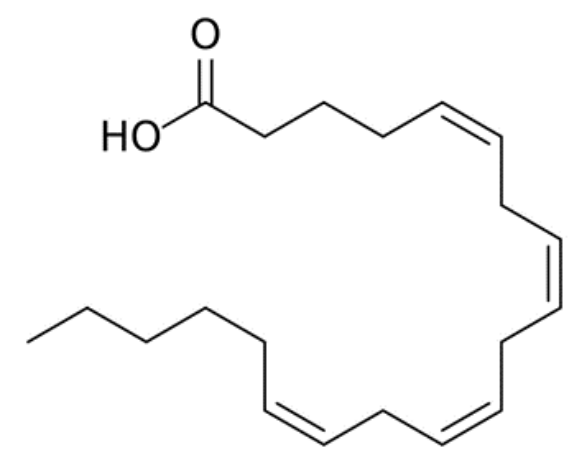

C<smiles>CCCCC/C=C\C/C=C\C/C=C\C/C=C\CCCC(=O)NCCO</smiles>

Figure 7. Chemical formula of capsaicin (A), anandamide (B) and arachidonic acid (C) 


\subsubsection{Kynurenic acid}

Degradation of the essential amino acid, tryptophan, along the kynurenine pathway yields several neuroactive intermediates (kynurenines) including kynurenic acid (4-oxo-1Hquinoline-2-carboxylic acid, KYNA; Figure 8.). It is synthesized in the central nervous system, including the spinal cord, predominantly by glial cells and it is found in low concentrations (10$150 \mathrm{nM}$ ) both centrally and peripherally (Bohar et al., 2015; Moroni et al., 1988; Nemeth et al., 2005; Pawlak et al., 2000; Schwarcz et al., 2002; Turski et al., 1988; Urbanska et al., 2000; Vecsei et al., 1991). Kynurenines participate in immunoregulation, inflammation and possess pro- or anti-excitotoxic properties, also their involvement in oxidative stress has been suggested. Kynurenines have been closely related to neurodegenerative diseases, such as Alzheimer's, Parkinson's and Huntington's diseases, amyotrophic lateral sclerosis and multiple sclerosis. However, KYNA is generally thought to have neuroprotective properties (Bohar et al., 2015). KYNA interacts with a multitude of molecular targets in the central nervous system. It is an excitatory amino acid receptor antagonist with preferential activity at the N-methyl-Daspartate (NMDA) receptors, acting at the glycine (half-maximal inhibitory concentration: $\mathrm{IC}_{50}$ $\sim 20 \mu \mathrm{M}$ ) and the NMDA recognition sites ( $\mathrm{IC}_{50} \sim 200 \mu \mathrm{M}$ ) (Carpenedo et al., 2001; Ganong et al., 1983; Hilmas et al., 2001; Prescott et al., 2006; Rozsa et al., 2008; Stone, 1993; Stone, 2000; Vecsei et al., 2013). In higher concentrations (0.1-1 mM) it also antagonizes the $\alpha$-amino-3hydroxy-5-methyl-4-isoxazole propionic acid (AMPA) /kainate receptors. KYNA is a potent noncompetitive antagonist at alpha 7 nicotinic acetylcholine receptors $\left(\mathrm{IC}_{50} \sim 7 \mu \mathrm{M}\right.$ ), too (Hilmas et al., 2001; Prescott et al., 2006; Stone, 1993; Stone, 2000). Finally, with $\mathrm{EC}_{50}$ in the micromolar concentration range, KYNA also activates the orphan G-protein receptor 35 (GPR35) (Cosi et al., 2011; Moroni et al., 2012; Szalardy et al., 2012; Wang et al., 2006).

Earlier data showed that intrathecal (IT) administration of KYNA caused antinociception accompanied with a reversible, dose-dependent motor impairment similarly to the local anesthetics (Horvath et al., 2006; Kekesi et al., 2002; Raigorodsky et al., 1990; Yaksh, 1989; Yamamoto et al., 1992; Zhang et al., 2003). Since its effect on VGSC has not yet been investigated, therefore, it cannot be excluded that these effects were produced, at least partially, by VGSC blockade. 


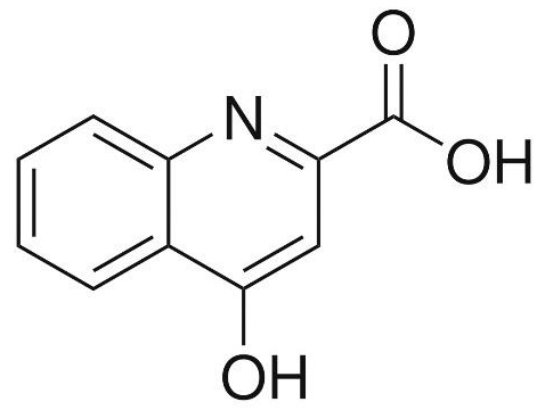

Figure 8. Chemical formula of kynurenic acid

\subsection{Methodological background}

As it was discussed above, the motor nerves have primarily VGSCs and VGKCs at the node of Ranvier, while sensory fibers have several other ligand binding sites as well, which can influence the excitability of these neurons. Therefore, models containing only motor fibers may provide a simple way for the in vivo modulation of the voltage gated channels involved in the action potential, especially VGSCs. Marginal mandibular branch of the facial nerve in rats, that controls the muscle activity of the vibrissae, contains only motor fibers. Even muscle spindles are lacking in vibrissae muscles (Fundin et al., 1994; Semba et al., 1986), therefore it can be an appropriate model for moderately selective influence of these channels (Figure 9. A).

Since facial nerve innervation in humans and rodents or lagomorphs is similar, rats and rabbits have often been used as model systems for studying its function and regeneration (Angelov et al., 2005; Guntinas-Lichius et al., 2005; Heaton et al., 2008; Ozcan et al., 2018). The facial nerve provides innervation of superficial muscles of the face, including those surrounding the mouth and eyes. Whisker excursion, or "whisking," is the most readily measurable facial movement in the rat. It is produced by the combined action of extrinsic whisker pad muscles and intrinsic "sling" muscles attached to each of the approximately 25 dynamically controlled vibrissae within the pads (Figure 9. B). Whisker pad muscles are innervated by the buccal and marginal mandibular branches of the facial nerve. Both branches are capable of supporting dynamic whisking (Heaton et al., 2008; Hohmann et al., 2014). The sensory innervation of the vibrissal pad is provided by the trigeminal nerve, mainly by the infraorbital nerve (Gao et al., 2001; Rhoades et al., 1983). 
The whisker muscles are easily accessible in these animals, and their movements could provide useful information about nerve functioning and regeneration; therefore, they have been frequently used for these goals (Heaton et al., 2008). However, it is supposed that this nerve can also be applied to test in vivo effects of different ligands acting primarily on the VGSCs.
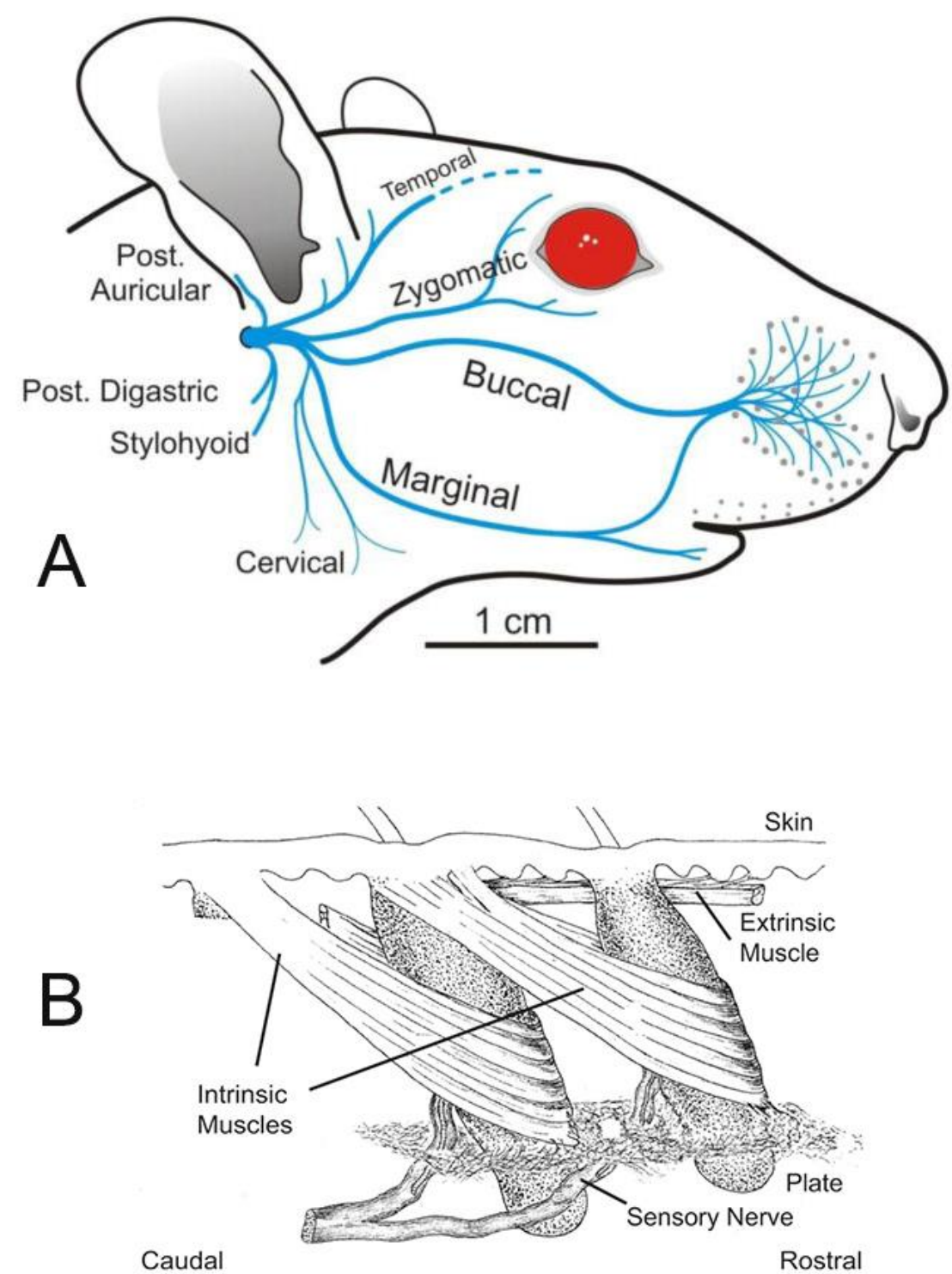

Figure 9. Anatomical background. A) A schematic anatomic illustration of the facial nerve and its branches. The marginal mandibular branch, the subject of our study, is shown in the lower facial region (Henstrom et al., 2012). B) The musculature and follicular anatomy of the vibrissal pad (Dorfl, 1982). 
The histological and functional patterns of the mandibular branch of the facial nerve of Wistar rats were described by Bento et al. (Bento et al., 2017). Mattox and Felix were the pioneers of stimulating the facial nerve in multiple segments (trunk, buccal and mandibular branches), thereby registering the responses with subcutaneous electrodes located on the upper and lower lips of rats (Mattox et al., 1987).

This model was chosen for our electrophysiological study, because the mandibular branch has a number of desirable qualities that makes it ideal for the surgical protocol: (1) It passes below and not inside the parotid gland simplifying its surgical exposure. The easy visualization of the nerve makes it possible to exclude animals with anatomical variations, such as branches to the upper lip, or anastomosis between the stimulus and the drug administration site, which could lead to bypass stimuli compromising the results of the electrophysiological tests. (2) The mandibular branch is a purely motor extratemporal segment of the facial nerve, having a 10 to $12 \mathrm{~mm}$ long path before splitting compared with the facial nerve trunk's $6 \mathrm{~mm}$ length. (3) It shows homogeneous histology with (4) less complex anatomy compared with the temporal and zygomatic branches. (5) It resemblance to the human facial nerve thus promoting a highly reproducible test (Bento et al., 2017).

Electrodiagnostic studies, originated in the 19th century, are consistently used over the past 3040 years. The most common tests are nerve conduction studies (NCS) and electromyography (EMG).

Conventional goal of NCS is to provide information about the electrical response of the muscle in order to determine the characteristics of nerve responses in the clinical practice. NCS are performed by placing electrodes on the skin and stimulating the nerves through electrical impulses. To study motor nerves, electrodes are placed over a muscle that receives its innervation from the tested (stimulated) nerve that helps to differentiate the malfunctioning part of the neuromuscular unit (Heaton et al., 2008; Hohmann et al., 2014).

EMG is the process by which electrode is inserted into a particular muscle and the electrical activity of that muscle is registered. This electrical activity comes from the muscle itself electric impulse is not used to stimulate the muscle. The EMG does not involve actually testing nerves, but it provides information indirectly about them (Weiss et al., 2004).

EMG and NCS are clearly two different electrodiagnostic methods, however, both of them are often referred to as just EMG, thus EMG as an umbrella term was used in our study, too. 


\section{Goals}

- The first aim of this study was to evolve an in vivo model, appropriate for examining VGSC-mediated effects on nerves containing only motor fibers, and for testing different drugs with different chemical properties (Fundin et al., 1994; Semba et al., 1986).

- The second goal was to test the reliability of the model by testing the efficacy of three classical local anesthetics (lidocaine, bupivacaine, ropivacaine) on motor nerve function.

- The third goal was to investigate the in vivo potency of the permanently charged sodium channel blocker QX-314 on motor fibers. The possible drug interactions of the combination of QX-314 with lidocaine, as a new way for local anesthesia, was also examined.

- Additionally, the effects of nisoxetine on VGSC and its conduction blocking efficacy in our animal model were also investigated.

- The next aim was to provide in vivo results regarding the VGSC blocking capability of capsaicin, AA and AEA.

- Since intrathecally administrated KYNA produced effects similar to classical local anesthetics', our last goal was to provide information about its potency on VGSC. 


\section{Methods}

\subsection{Animals and drugs}

All experiments were carried out with the approval of the Hungarian Ethical Committee for Animal Research (Registration number: XIV./3754/2012). Wistar rats were anesthetized with an intraperitoneally injected mixture of ketamine $(72 \mathrm{mg} / \mathrm{kg})$ and xylazine $(8 \mathrm{mg} / \mathrm{kg})$.

The following drugs were administered perineurally: lidocaine (MW: 234; Lidocaine; Egis Pharmaceuticals PLC, Budapest, Hungary), bupivacaine (MW: 288.43; Actavis, Weston, Florida, USA), ropivacaine (MW: 238.9; Naropin, AstraZeneca, London, United Kingdom), AEA (MW: 347), AA (MW: 304.5), QX-314 (MW: 263) (all three drugs from Sigma-Aldrich, Budapest, Hungary), nisoxetine (MW: 307) and KYNA (MW: 189) (both ligands from Tocris, Budapest, Hungary), and capsaicin (MW: 377; Plantakem Kft., Sándorfalva, Hungary). AA was dissolved in $10 \%$ ethanol, AEA in $10 \%$ ethanol $+4 \%$ Tween 80 , and capsaicin in $10 \%$ ethanol $+10 \%$ Tween 80 . QX-314 was dissolved in phosphate buffered saline (PBS; at pH =7.4) (Liu et al., 2011). KYNA, was dissolved in $0.1 \mathrm{M} \mathrm{NaOH}$ and the excess $\mathrm{NaOH}$ was backtitrated with $0.1 \mathrm{M} \mathrm{HCl}$ to neutral $\mathrm{pH}$. All the stock solutions were further diluted with saline.

\subsection{Experimental setup}

The facial area of the anesthetized animals was shaved, an "L"-shape incision was made and the skin was gently elevated to expose the marginal mandibular branch of the facial nerve at buccal level (Figure 10.). Both the buccal and marginal mandibular branch had to be explored to exclude areas containing anastomosing braches. The proximal part was wrapped with a unipolar wire electrode $(0.1 \mathrm{~mm})$ for electrical stimulation to induce the whisker movement. Unipolar needle (26-gauge) electrodes were placed into the whisker area of the rats to investigate muscle activity (Figure 11.). The visual finding had to be consistent with the electrophysiological data seen on the computer screen. The ground electrode was placed subcutaneously, close to the nerve and the muscle. The revealed area was protected against drying-up by continuous coverage of paraffin film dropped onto the surgery site. The stimulations with rectangular biphasic pulses of constant current were delivered through a stimulator with a supramaximal stimulus ( $1 \mathrm{~mA}$ for $250 \mu \mathrm{s})$, and EMG activities after repeated single stimuli were recorded. EMG recordings were amplified (Model 1700 Differential AC 
Amplifier, A-M Systems, Carlsborg, WA), sampled at $20 \mathrm{kHz}$ with an A/D board, filtered (100 $\mathrm{Hz}$ to $5 \mathrm{kHz}$ ), and stored on a computer running software. The maximal amplitude was determined as a difference between the highest positive and lowest negative peak of the compound action potential (Figure 12.). Amplitudes and peak-latencies (if there were any) were analyzed.
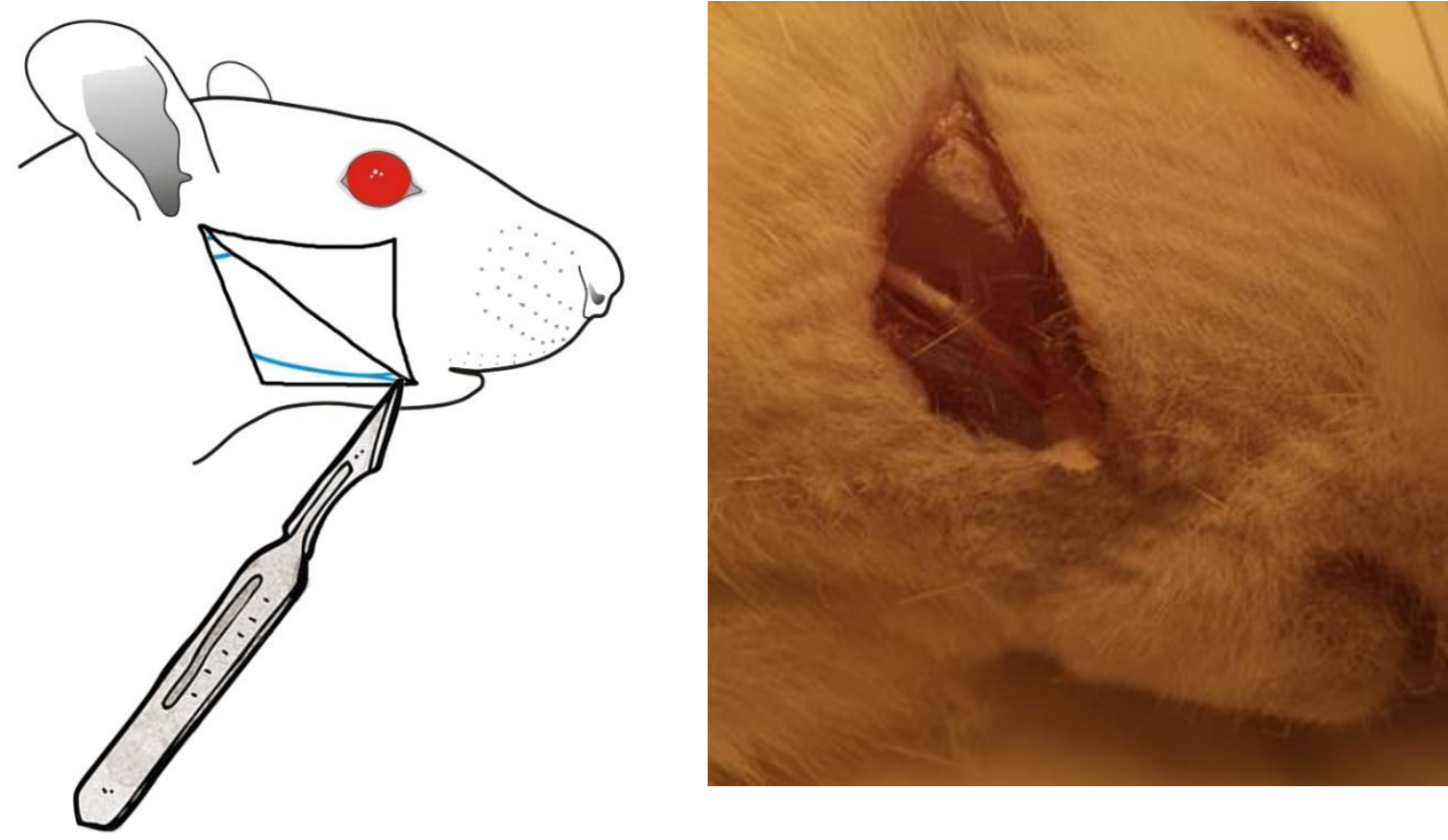

Figure 10. Surgical exposure of the marginal mandibular branch of the facial nerve. " $L$ "shape incision to expose the facial nerve at buccal level. 
$\mathbf{A}$

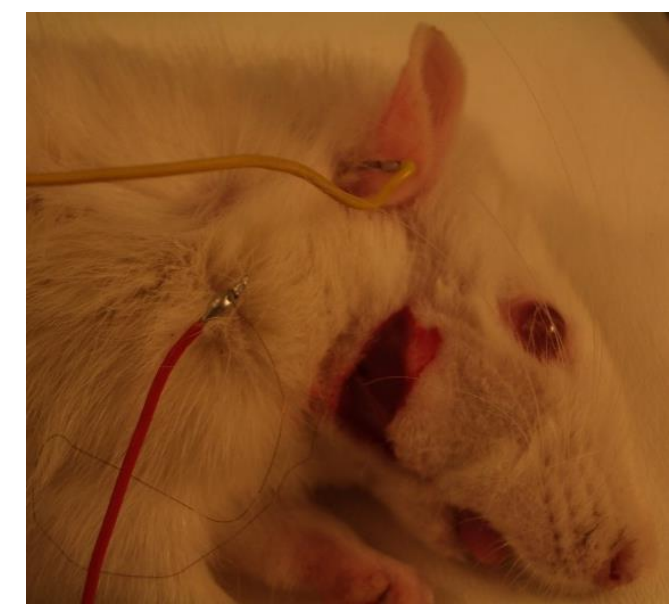

B

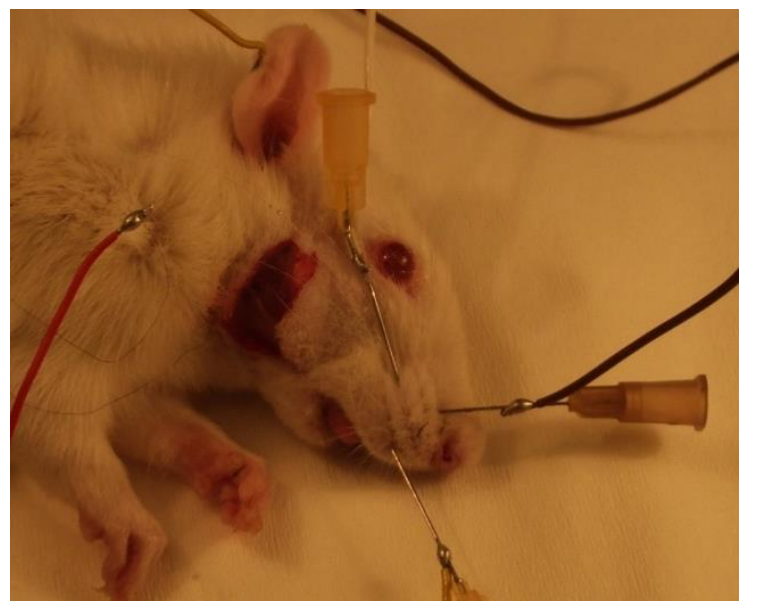

Figure 11. Positions of stimulating (A) and registration (B) electrodes.

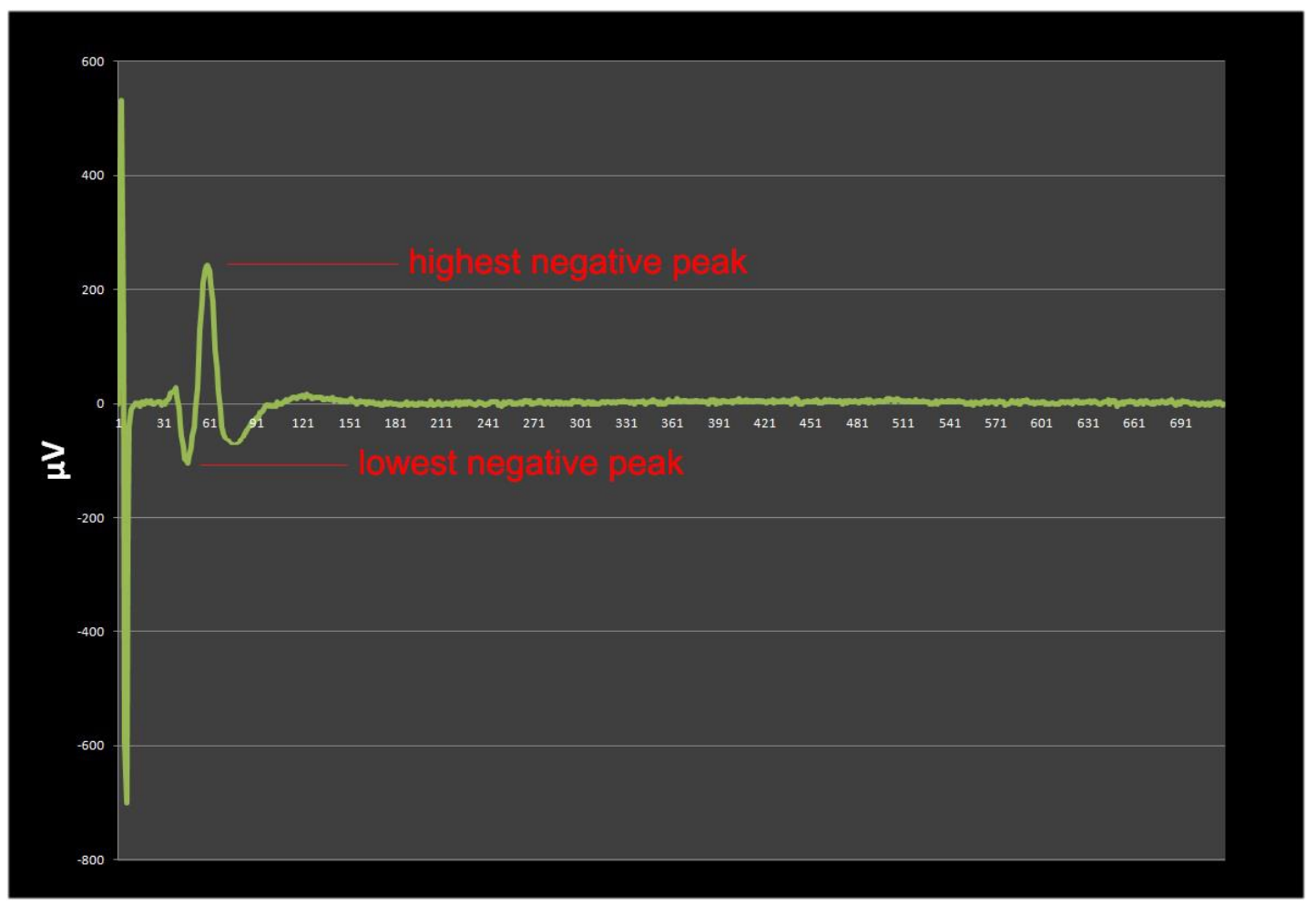

Figure 12. An EMG recording of the compound action potential. 


\subsection{Experimental protocol}

After 3 consecutive determinations of EMG activities (baseline) with 2 min intervals, the effects of the different ligands were investigated. Drugs were applied perineurally distal to the stimulating electrode in $20 \mu \mathrm{L}$ volume. A 26-gauge stainless steel needle was attached via a polyethylene tube (PE 20) to a $50 \mu$ l Hamilton syringe (Hamilton Co., Bonaduz, Switzerland) that was operated manually. The different doses of the applied drugs are shown in Table 3.

Because of its lower solubility, $190 \mathrm{nmol}(50 \mu \mathrm{g})$, the half of the original OX-314 dose, was applied together with $21.4 \mathrm{nmol}(5 \mu \mathrm{g})$ or $85.5 \mathrm{nmol}(20 \mu \mathrm{g})$ lidocaine in combination studies. KYNA was applied only in a high dose $(528.6 \mathrm{nmol} ; 100 \mu \mathrm{g})$, because IT administration of this dose caused total flaccid paralysis (Verberne et al., 1990).

The number of the animals in the different groups were between 6-10. The measurements were repeated 30,60, 90, $120 \mathrm{~s}$ after the drug administration, and then in 2 minute intervals for 30 min in total (Figure 13.). The mean values between $0.5-2,4-10,12-20$ and $22-30$ min intervals were analyzed as $1^{\text {st }}, 2^{\text {nd }}, 3^{\text {rd }}$ and $4^{\text {th }}$ time periods.

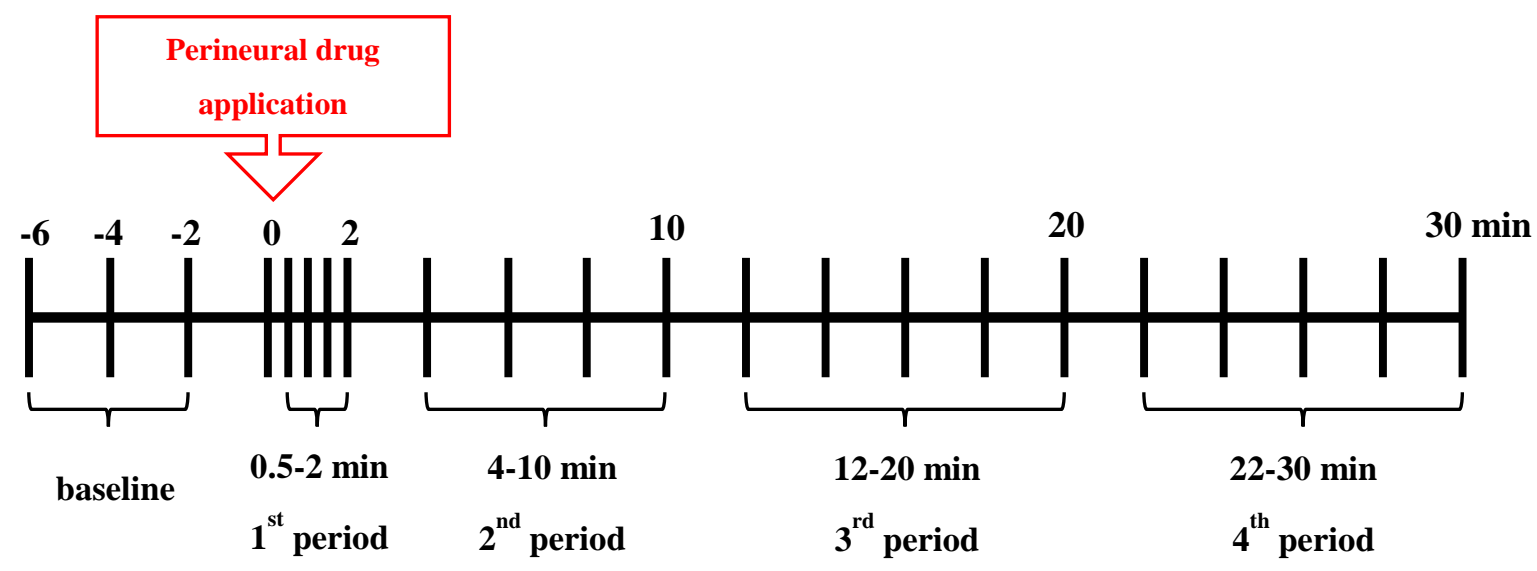

Figure 13. Timeline of the experimental protocol 
Applied doses

\begin{tabular}{|c|c|c|}
\hline Drugs & $\mu \mathrm{g}$ & nmol \\
\hline \multirow{3}{*}{ lidocaine } & 5 & 21.4 \\
\hline & 20 & 85.5 \\
\hline & 50 & 213.7 \\
\hline \multirow{3}{*}{ bupivacaine } & 5 & 17.3 \\
\hline & 20 & 69.3 \\
\hline & 50 & 173.4 \\
\hline \multirow{3}{*}{ ropivacaine } & 5 & 18.2 \\
\hline & 20 & 72.9 \\
\hline & 50 & 182.2 \\
\hline QX-314 & 100 & 380 \\
\hline \multirow{2}{*}{ lidocaine + QX-314 } & $5+50$ & $21.4+190$ \\
\hline & $20+50$ & $85.5+190$ \\
\hline \multirow{3}{*}{ nisoxetine } & 50 & 184.3 \\
\hline & 100 & 368.5 \\
\hline & 200 & 737.0 \\
\hline \multirow{3}{*}{ capsaicin } & 125 & 331.5 \\
\hline & 250 & 663 \\
\hline & 500 & 1326 \\
\hline \multirow{3}{*}{ AA } & 100 & 328.4 \\
\hline & 200 & 656.8 \\
\hline & 400 & 1313.6 \\
\hline \multirow{4}{*}{ AEA } & 25 & 72 \\
\hline & 100 & 288 \\
\hline & 200 & 576 \\
\hline & 400 & 1152 \\
\hline KYNA & 100 & 528.6 \\
\hline
\end{tabular}

Table 3. The doses of applied drugs.

Abbreviations: KYNA - kynurenic acid; AA - arachidonic acid; AEA - anandamide 


\subsection{Statistical analysis}

Data are presented as means \pm SEM. Amplitudes were normalized by calculating the percentage change from baseline (mean of the 3 baseline values) for each post-injection data point by the following formula:

Relative Amplitude $(\%)=($ observed amplitude/baseline amplitude $) \times 100$

Therefore, $100 \%$ means no any effect of the drug on the amplitude of EMG activity, while 0\% means that there is no EMG response after the stimulus.

The area under the curve (AUC) values were obtained by calculating the area during the $30 \mathrm{~min}$ period following the injection to construct dose response curves for the different ligands. $\mathrm{AUC}_{\min }(0)$ value would mean the complete disappearance of $\mathrm{EMG}$ responses, while $\mathrm{AUC}_{\max }$ (2800) would mean the $100 \%$ value of the amplitudes of action potentials (no drug effect). The mean AUC values were used for linear regression analysis (least square method) to determine the $\mathrm{ED}_{50}$ values with $95 \%$ confidence intervals $(\mathrm{CI})$, which is equivalent to the dose that yielded $50 \%$ decrease in the amplitude of action potentials for the whole period $\left(\left[\mathrm{AUC} \mathrm{C}_{\min }+\mathrm{AUC}_{\max }\right] / 2\right.$ $=1400)$.

The time-course effects were examined by repeated measurement of ANOVA. The post-hoc comparison was calculated by using the Newmann-Keuls test (p value $<0.05$ was considered significant). Statistical analyses were performed with STATISTICA for Windows version 12 (Statistica Inc., Tulsa, Oklahoma, USA) and GraphPad Prism (GraphPad software Inc. La Jolla, California, USA) softwares. 


\section{Results}

Marginal mandibular motor nerve stimulations produced action potentials (Figure 12.) with visible whisker movements. Both the latency and the amplitude of EMG responses were stable during the investigated period in the vehicle treated groups (Figure 14.). The latency of the first positive peak appeared at $1.9 \pm 0.02 \mathrm{~ms}$, while the second negative one at $2.9 \pm 0.04 \mathrm{~ms}$. The mean baseline amplitude was $2.8 \pm 0.1 \mathrm{mV}$. The analysis of the peak latencies (if any response was detected) did not reveal significant effects of any drugs, i.e., peak latencies were not influenced significantly by any treatment (data are not shown); thus, only the amplitude changes were analyzed.

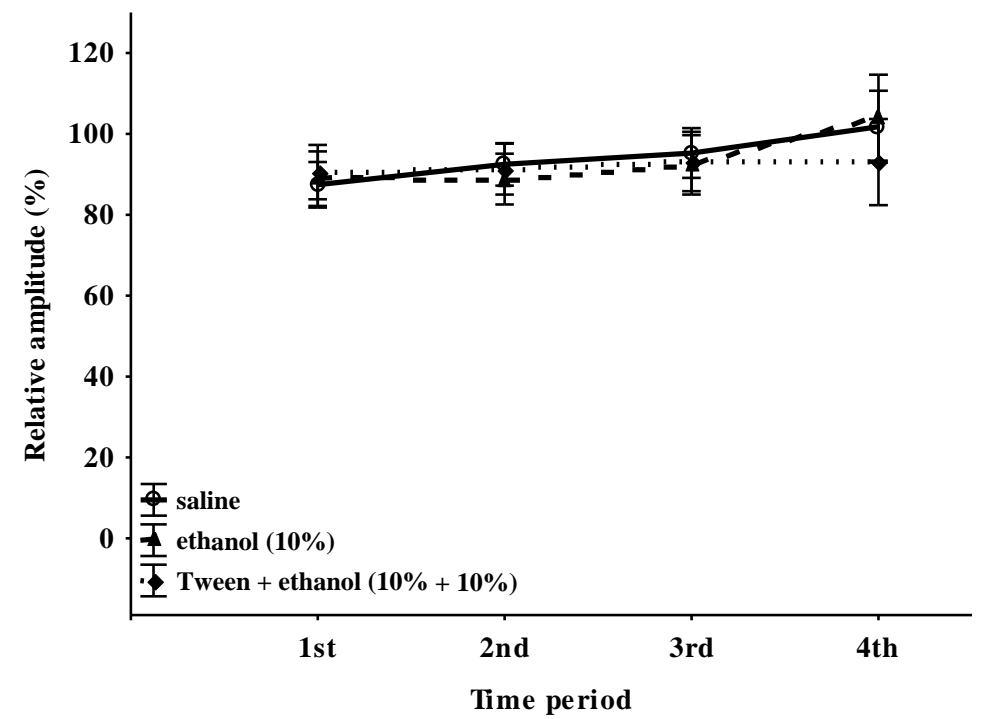

Figure 14. EMG activity after the application of different vehicles. 


\subsection{Classical local anesthetics}

Regarding the effects of lidocaine, significant effects of doses $\left(F_{3,37}=33.6 ; \mathrm{p}<0.001\right)$ and time $\left(F_{3,111}=8.3 ; \mathrm{p}<0.001\right)$ were observed (Figure 15. A). ANOVA also showed significant effects of doses $\left(F_{3,28}=17.0, \mathrm{p}<0.001\right)$, time $\left(F_{3,84}=20.8 ; \mathrm{p}<0.001\right)$ and interaction $\left(F_{9,84}=10.0\right.$; $\mathrm{p}<0.001$ ) in case of bupivacaine administrations (Figure 15. B). Similarly, ANOVA showed significant effects of doses $\left(F_{3,27}=24.3, \mathrm{p}<0.001\right)$, time $\left(F_{3,81}=9.8 ; \mathrm{p}<0.001\right)$ and interaction $\left(F_{9,81}=9.0 ; \mathrm{p}<0.001\right)$ in case of ropivacaine administrations (Figure 15. C). All of these drugs produced prolonged EMG depression in higher doses. The linear regression curves of AUC data showed dose dependent effects of all ligands with slight potency differences among them (Figure 16.); thus, the $\mathrm{ED}_{50}$ value was the highest for lidocaine [75.9 (CI: 61.0-93.3) nmol], while bupivacaine [34.7 (CI: 21.1-58.1) nmol] and ropivacaine [36.3 (CI: 23.0-72.3) nmol] had slightly higher potency. The post-hoc analysis showed that both 85.5 and $213.7 \mathrm{nmol}$ of lidocaine treatment had significant effect during all time periods. Bupivacaine $(69.3,173.4$ $\mathrm{nmol})$ and ropivacaine $(182.2 \mathrm{nmol})$ blocked significantly the nerve conduction from the $2^{\text {nd }}$ to the $4^{\text {th }}$ time period, while the lower dose of ropivacaine $(72.9 \mathrm{nmol})$ showed similar effect in all time periods. Regarding their effects at the $1^{\text {st }}$ period lidocaine was more effective than the other two drugs, indicating its faster effect. However, the effect of lidocaine slightly decreased during the $4^{\text {th }}$ period, while ropivacaine and bupivacaine resulted in a prolonged anesthesia. 

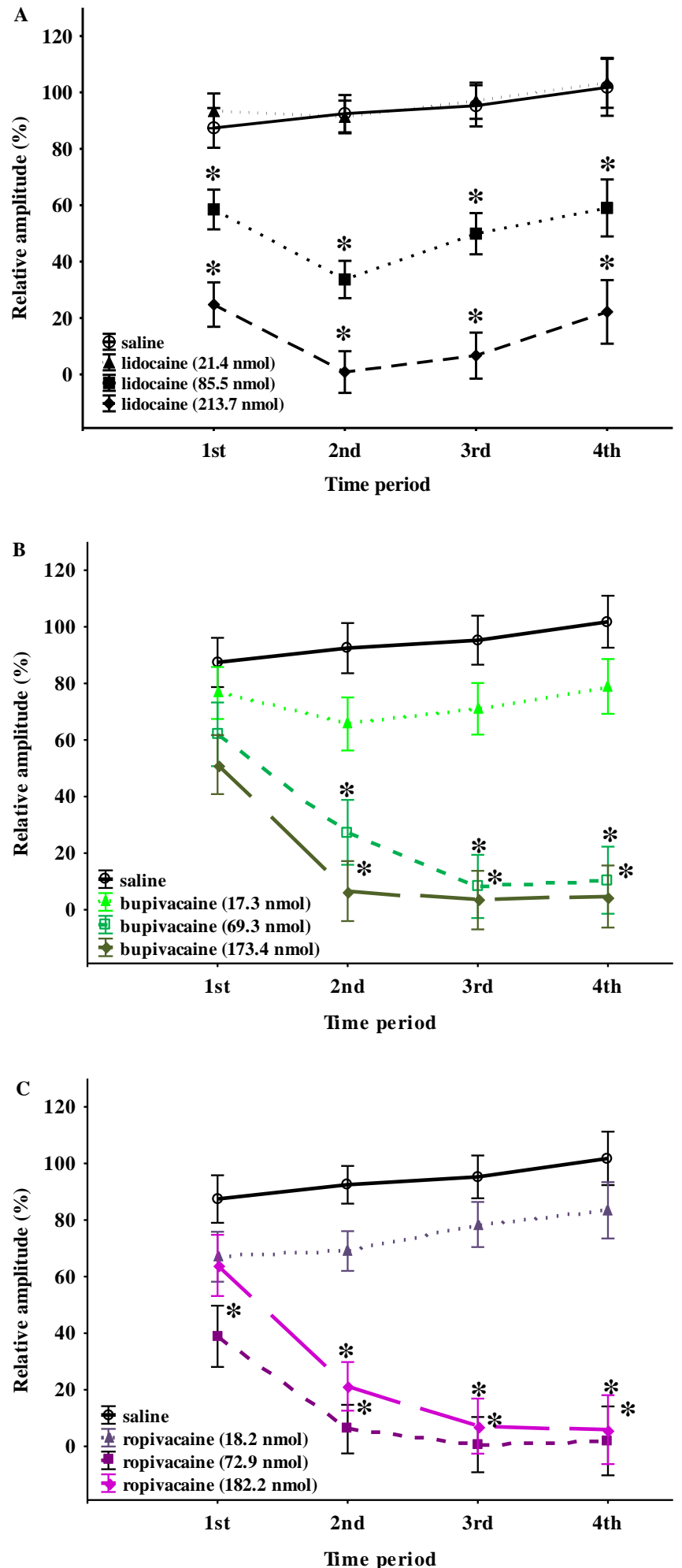

Figure 15. Time response curves of different doses of lidocaine (A), bupivacaine $(B)$ and ropivacaine $(C)$ on EMG activity. The * symbol signs significant difference $(p<0.05)$ compared to the saline-treated group on the time response figures. 


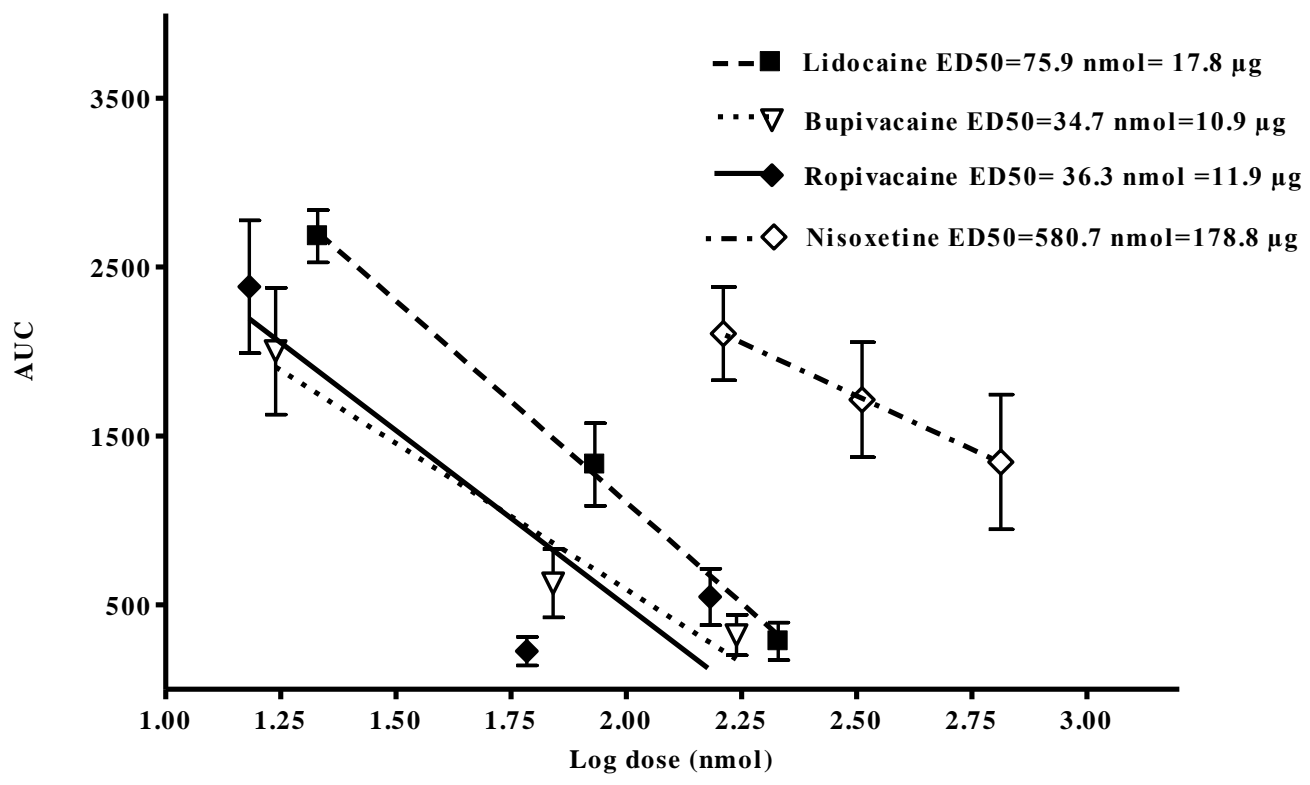

Figure 16. Linear regression curves of AUC values for lidocaine, bupivacaine, ropivacaine and nisoxetine.

\subsection{QX-314}

Regarding the application of QX-314 (380 nmol) by itself, it did not produce any effect on EMG activity (data are not shown). Comparing the effect of the $21.4 \mathrm{mmol}$ lidocaine with the lidocaine-QX-314 combination revealed significant interaction $\left(F_{3,75}=7.03 ; \mathrm{p}<0.001\right)$, and close to significant effect of treatment $(\mathrm{p}=0.051$; Figure 17. A). The higher dose combination (190 nmol QX-314 with $85.5 \mathrm{nmol}$ lidocaine) caused significant effects of time $\left(F_{3,51}=6.6\right.$; $\mathrm{p}<0.001)$ and interaction $\left(F_{3,51}=4.3 ; \mathrm{p}<0.01\right.$; Figure 17. B $)$. The post-hoc analysis showed that the lower dose combination (190 nmol QX-314 with 21.4 nmol lidocaine) was significantly more effective in the $4^{\text {th }}$ time period compared to the 21.4 nmol lidocaine alone. The significant interactions indicate that QX-314 prolonged the effects of lidocaine in both combinations. 

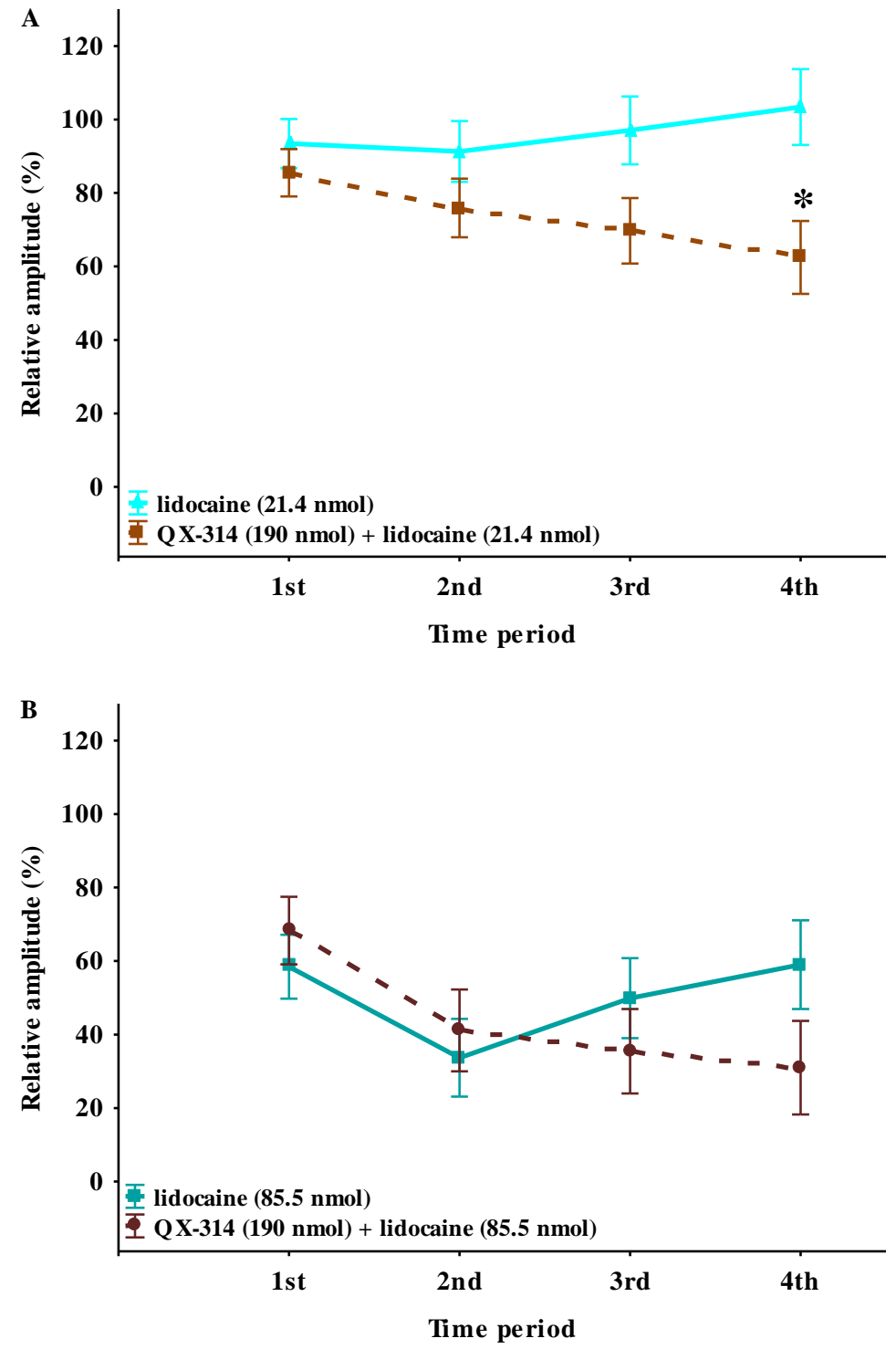

Figure 17. EMG activity after lidocaine application in low $(21.4 \mathrm{nmol})$ dose alone and combined with QX-314 (A); and in high (85.5 nmol) dose alone and combined with QX-314 $(B) . T h e *$ symbol signs significant differences $(p<0.05)$ from the lidocaine-treated group.

\subsection{Nisoxetine}

Regarding the nisoxetine treatment, ANOVA showed significant effects of dose $\left(F_{3,30}=3.5, \mathrm{p}<\right.$ $0.05)$, time $\left(F_{3,90}=12.0 ; \mathrm{p}<0.001\right)$ and their interaction $\left(F_{9,90}=4.6 ; \mathrm{p}<0.001\right)$ (Figure 18.). The post-hoc analysis showed significant effect only in the highest $737.0 \mathrm{nmol}$ dose compared to the control group in the $4^{\text {th }}$ time period. The linear regression curve of nisoxetine revealed that 
it had very low potency [ED50: 580.7 (CI: 206.5-1633.1) nmol] compared to the classical local anesthetic drugs (Figure 16.).

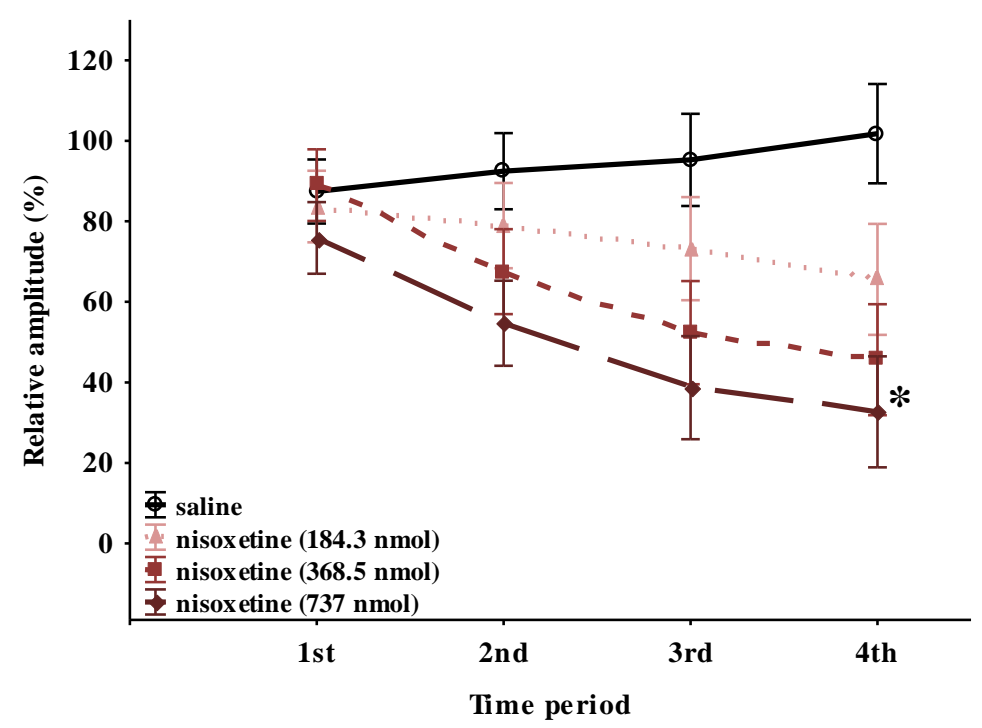

Figure 18. The time-response curves of different doses of nisoxetine on EMG activity. The * symbol signs significant difference $(p<0.05)$ from the saline-treated group.

\subsection{Capsaicin, arachidonic acid and arachidonoyl ethanolamide}

As regards the capsaicin treatment, ANOVA showed significant effects of dose $\left(F_{3,25}=4.4, p<\right.$ $0.05)$, time $\left(F_{3,75}=4.7 ; p<0.005\right)$ and their interaction $\left(F_{9,75}=4.5 ; p<0.001\right)$; thus, $663 \mathrm{nmol}$ produced about $50 \%$ inhibition, and the post-hoc analysis showed significant differences between the vehicle and capsaicin application in the $3^{\text {rd }}$ and $4^{\text {th }}$ time periods (Figure 19. A). ANOVA showed significant effects of treatment $\left(F_{4,28}=2.7, p<0.05\right)$ after AEA application; thus, 567 nmol produced about 50\% inhibition, but the post-hoc analysis did not show significant differences between the vehicle and AEA at any time points (Figure 19. B). Regarding the effects of AA, it did not produce significant inhibition on the evoked action potentials even in high doses (Figure 19. C). The linear regression analysis did not show significant dose response for these ligands; therefore, $\mathrm{ED}_{50}$ values could not be calculated. 

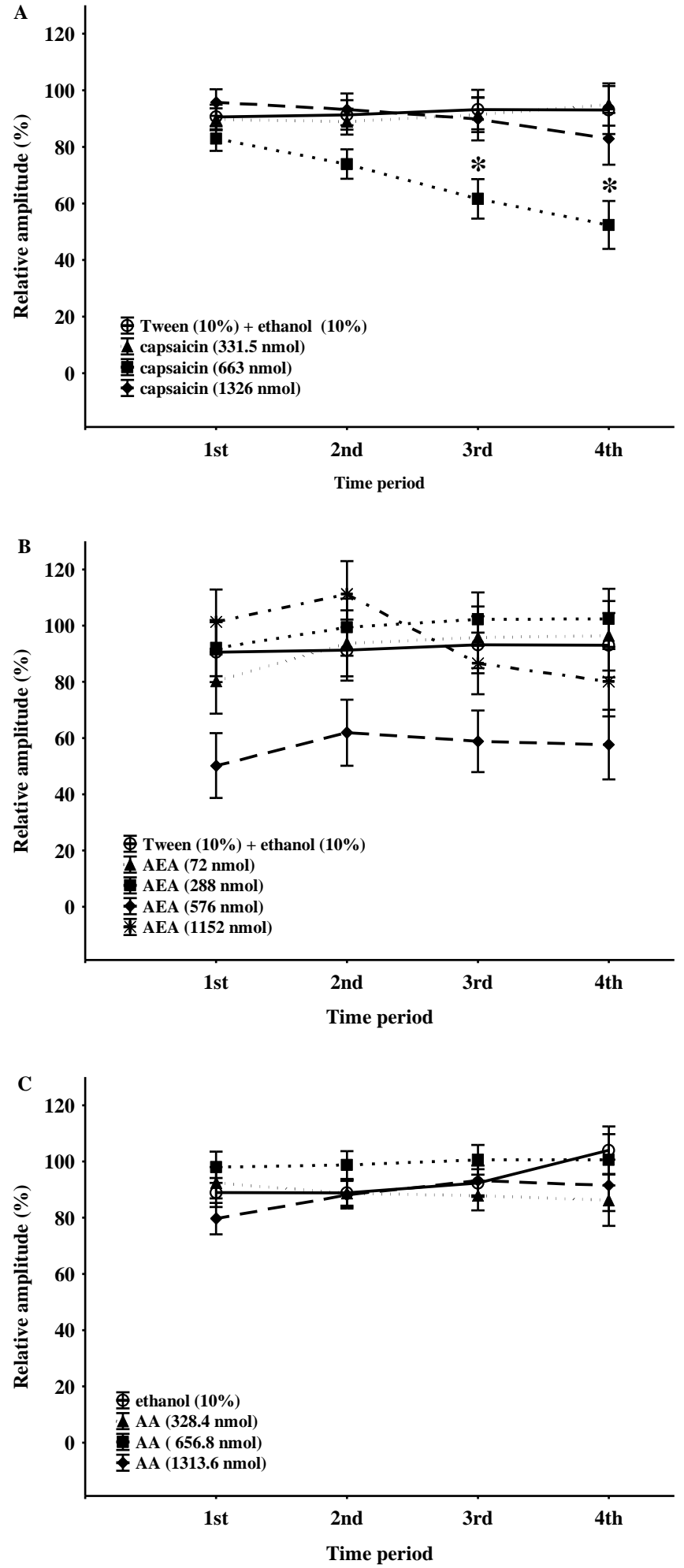

Figure 19. The time-response curves of different doses of capsaicin (A), $A E A(B)$ and $A A(C)$ on EMG activity. The * symbol signs significant difference $(p<0.05)$ from the saline-treated group. 


\subsection{Kynurenic acid}

The perineural administration of high dose KYNA $(528.6 \mathrm{nmol}, 100 \mu \mathrm{g})$ that resulted motor impairment and antinociception at the spinal level, did not influenced the evoked responses (Figure 20.).

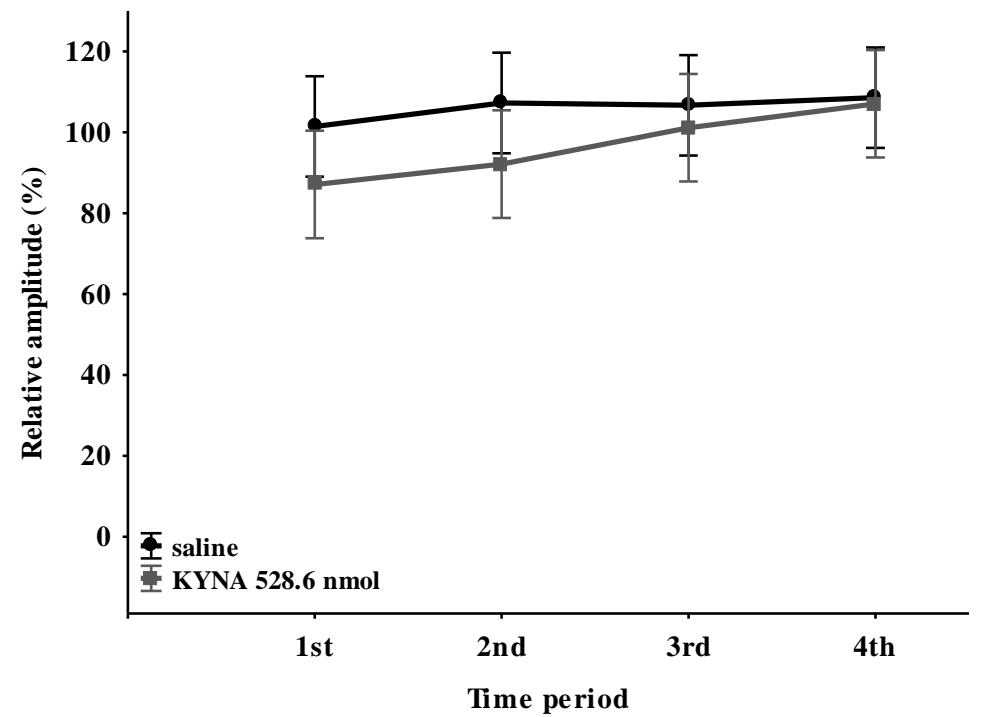

Figure 20. The time-response curve of kynurenic acid (KYNA) on EMG activity. 


\section{Discussion}

The present results revealed that this in vivo model can provide reliable data, for at least half an hour, about the motor nerve excitability, since the responses to repeated stimuli did not change during this period, and none of the vehicles caused changes in the stimulus-response curves.

\subsection{Local anesthetics}

We showed that classical local anesthetics inhibited the evoked action potentials with high potency in a nerve containing motor fibers exclusively. In accordance with previous observations (Sisk, 1992), slight potency differences were found between these ligands. Bupivacaine and ropivacaine had almost the same potency on EMG activity, and this was moderately higher compared to lidocaine. Furthermore, the effects of lidocaine developed faster with shorter duration compared to the other two drugs. These results are in agreement with data obtained in human subjects, and partially, with their lipid solubility; i.e., the octanol/buffer partition coefficient of lidocaine is the lowest, which might lead to its lower potency (Strichartz et al., 1990) (Table 2.).

Furthermore, it was revealed that QX-314 did not produce any effects on motor fiber function by itself, but it slightly prolonged the effect of lidocaine in agreement with the earlier behavioral studies, which described a potentiated motor paralysis after perisciatic co-administrations of QX-314 with bupivacaine or lidocaine (Binshtok et al., 2009; Brenneis et al., 2014; Roberson et al., 2011). As it was mentioned in the Introduction, QX-314 can produce selective inactivation of VGSCs in sensory neurons by entering the cells through TRPV channels (expressed only in the sensory fibers), therefore, its topical administration alone does not influence the motor functions (Binshtok et al., 2007; Binshtok et al., 2009; Kim et al., 2010; Shen et al., 2012). Until now only one study has recorded the EMG activity from the digastric muscle to painful stimuli of the dental cavity after QX-314 (and/or capsaicin) administration (Kim et al., 2010). The inferior alveolar nerve, as a sensory afferent, and the mylohyoid motor nerve, as a motor efferent were tested separately. QX-314 and capsaicin together blocked the inferior alveolar nerve, which expresses TRPV1 channels, but not the motor nerve lacking them. However, it was found that perisciatic (mixed nerve) application of QX-314 in very high doses can produce temporary motor impairments (Lim et al., 2007; Roberson et al., 2011). Regarding the action mechanism of the effect of QX-314 and lidocaine co-administration, several 
possibilities can be suggested. Since the QX-314 cannot influence the VGSC extracellularly, pharmacokinetic interaction between the two ligands such as their binding to plasma proteins can modify the elimination of lidocaine (Taheri et al., 2003). Furthermore, it has been recently shown that bupivacaine and lidocaine can cause QX-314 accumulation in cells, which do not express TRPV1 or transient receptor potential cation channel subfamily A member 1 (TRPA1) channels, and it also induces a prolonged block of $\mathrm{C}$-fibers of isolated sciatic nerves in TRPA1TRPV1 double knockout mice (Brenneis et al., 2014). Additionally, the analgesia and motor block produced by the co-application of bupivacaine and QX-314 to rat sciatic nerve was not abolished by ruthenium red (TRP channel blocker). It is suggested that the mechanism of this potentiation is not confined to TRP channel activation; however, this phenomenon most likely relies on the interaction of the local anesthetics and the lipid bilayer itself (Brenneis et al., 2014). Most local anesthetics can affect the physical structure of membrane bilayers by interaction with cholesterol, e. g. lidocaine decreases lipid density in membranes and lowers membrane thickness in model membranes, and interestingly even QX-314 fluidizes phosphatidylserinecontaining nerve cell model membranes (Brenneis et al., 2014; Yi et al., 2012). Thus, further experiments are required to reveal the exact mechanism of their interaction with the lipid bilayer.

\subsection{Nisoxetine}

Our results revealed that the noradrenaline reuptake inhibitor, nisoxetine, had a low potency in this model. Some data show that nisoxetine inhibits VGSCs in vitro models, and also produces dose dependent blockade during spinal anesthesia in rats (Hennings et al., 1999; Leung et al., 2013). Chen et al. have compared the local anesthetic effect of nisoxetine as infiltrative cutaneous analgesic to lidocaine in cutaneous trunci muscle reflex. In contrast to our results, nisoxetine had high inhibitory potency, suggesting that it inhibits the VGSCs (Chen et al., 2012). The controversy might be due to the differences in the applied model as the earlier study investigated only the sensory functions (Chen et al., 2012), and the multiple differences between the motor and sensory fibers could have led to decreased potency in motor fibers (Krishnan et al., 2009). 


\subsection{Capsaicin, arachidonic acid and arachidonoyl ethanolamide}

Our data firstly revealed the in vivo effects of the polyunsaturated fatty acid (AA), its derivative (AEA) and capsaicin on EMG activity, showing that AA was ineffective, while AEA and capsaicin had a modest blocking effect in high, but not in the maximally applied dose. Thus, in contrast to the in vitro results, our data suggest that they do not have significant effects on VGSCs in moderate doses.

As it was mentioned in the Introduction, functional studies suggested that TRPV1 and CB receptors are expressed peripherally on (primarily unmyelinated) sensory fibers (Bernardini et al., 2004; Domoki et al., 2003; Gamse et al., 1982; Sann et al., 1995; Santha et al., 2003; Sauer et al., 2009; Szigeti et al., 2012; Tominaga et al., 1998). Therefore, perineural capsaicin and the endogenous lipid, AEA, can influence the activity of these fibers by acting on these receptors. Since most of the peripheral nerves (e.g., the sciatic nerve) contain both sensory and motor fibers, it would be difficult to distinguish between the effects on TRPV1/CB1 receptors and VGSCs. There is no direct proof about the presence of TRPV1 or CB receptors on motor fibers, although a few studies have reported that perineural application of capsaicin did not influence the activity of myelinated fibers (Brenneis et al., 2013; Petsche et al., 1983; Weller et al., 2011). Earlier in vitro studies showed that AA and AEA can inhibit VGSC in high doses by a hyperpolarizing shift of the steady-state inactivation voltage independently of CB1 and CB2 receptor activations (Al Kury et al., 2014; Boland et al., 2008; Fang et al., 2011; Lee et al., 2002; Nicholson et al., 2003). Other studies have extended these observations by demonstrating that AEA is associated preferentially with an inactivated state of the sodium channel complex, and it can inhibit both the tetrodotoxin sensitive and insensitive sodium channels (Kim et al., 2005). It was also suggested that the AEA-induced antinociception in CB1 receptor knockout mice might have been due to the state-dependent inhibition of sodium currents in sensory neurons (Di Marzo et al., 2000). Intracellular AA application reversibly suppressed the $\mathrm{Na}^{+}$ current of squid giant axon with little effect on $\mathrm{K}^{+}$current (Elinder et al., 2017). In contrast to the in vitro results, our in vivo data showed that the AA did not produce any effects on the motor nerve activity, which might be due to its low potency at VGSCs and/or fast metabolism.

In vitro studies have presented that capsaicin also inhibits the VGSCs at a high concentration (>10 $\mu \mathrm{M})$ (Cao et al., 2007; Duan et al., 2007; Lundbaek et al., 2005; Nicholson et al., 2003; Wang et al., 2007; Yamanaka et al., 1984). These effects could be observed in TRPV1 KO mice 
and TRPV1 antagonist independent manner, even the TRPV1 receptor antagonist, capsazepine causes similar effects as capsaicin (Cao et al., 2007; Lundbaek et al., 2005; Wang et al., 2007). Both AEA and capsaicin caused a slight inhibition on EMG activity in high doses (capsaicin: $663 \mathrm{nmol}$; AEA: $576 \mathrm{nmol}$ ), but their largest applied doses (capsaicin: $1326 \mathrm{nmol}$; AEA: 1152 nmol) were ineffective. This $U$ shape dose-effect curves can be observed after administration of different peptide ligands, and it was not expected with these lipids. We cannot give an exact explanation for this phenomenon, but these ligands might alter the lipid bilayer elasticity; thus, a stiffening of the membrane can cause conformational changes in the channel proteins leading to alteration in the function of VGSCs in special doses (Duan et al., 2007; Jiang et al., 2012; Lundbaek et al., 2005). Another possible explanation can be, that some of the actions, described in the introduction, are active simultaneously causing a sum of effects that is detectable; furthermore, these cumulative effects might be dose-dependent. However, since the effective doses were very high, their pharmacological utilization is questionable. Furthermore, as it is reported PUFAs has an effect on VGKCs, we cannot call our model selective for VGSC in the case of AA and AEA.

\subsection{Kynurenic acid}

IT administration of KYNA produces antinociception in different pain models, but its effective doses also caused motor impairment similarly to the classical local anesthetics (Horvath et al., 2006; Kekesi et al., 2002; Raigorodsky et al., 1990; Yaksh, 1989; Yamamoto et al., 1992; Zhang et al., 2003). As mentioned in the Introduction, KYNA interacts with a multitude of molecular targets in the central nervous system, but the roles of the different receptors that may be influenced by KYNA in this phenomenon have scarcely been investigated, and the effect on VGSC should be excluded. As KYNA had no effects at high $(100 \mu \mathrm{g})$ dose on the motor nerve function, therefore, we suggest that the anesthetic effects of KYNA at the spinal level might not be due to the inhibition of VGSCs, but do the receptor antagonist effect at the NMDA receptors (Carpenedo et al., 2001; Ganong et al., 1983; Hilmas et al., 2001; Rozsa et al., 2008; Stone, 1993; Vecsei et al., 2013). These results show that KYNA is an ideal ligand with high bioavailability for the attainment of perfect, reversible spinal anesthesia (i.e. motor paralysis with no sensation) which might be beneficial during surgery (Kekesi et al., 2002). 


\subsection{Clinical relevance}

The selective blockade of sensory fibers is an important goal in the clinical practice. Since these fibers, besides the VGSCs and VGKCs, are rich in different binding sites, the targeting of these sites can provide a way for the discerning influence of these neurons. Since most of these binding sites are missing from motor fibers (have only VGSCs and VGKCs), our laboratory introduced a method for the separate investigation of voltage gated channels to exclude and/or disclose the in vivo effects of different ligands on them.

It was proved that the marginal mandibular branch of facial nerve, containing exclusively motor fibers, is an appropriate model for this goal, and it can provide reliable data for at least half an hour about the motor nerve excitability, and the classical local anesthetics inhibited the evoked action potentials with similar potencies as known from the clinical practice.

The low potencies of some of the investigated ligands (nisoxetine, capsaicin, arachidonic acid, anandamide) in this model suggest that the inhibition of these voltage gated channels have no significant role in their antinociceptive effects, therefore, these substances will not produce significant motor impairments. The ineffectiveness of kynurenic acid applied on the motor nerve revealed that its flaccid paralytic effects during IT administration might not be due to the block of these voltage gated channels. 


\section{Summary}

- We introduced an in vivo animal model for the evaluation of the effects of different ligands on nerves containing primarily motor fibers.

- It has been demonstrated that perineural application of classical local anesthetic ligands have high potency on nerves containing only motor fibers, suggesting that our model might be reliable and simple test for the investigation of the in vivo effects of different molecules primarily on the VGSCs. In agreement with previous studies, some degree of potency differences between the classical local anesthetics were found, thus lidocaine had slightly lower potency compared to the other two local anesthetics.

- QX-314 by itself did not influence the EMG activity, however, co-administration with lidocaine resulted a prolonged effect. This potentiation indicates some kinds of interaction between lidocaine and QX-314 in motor nerves.

- The low potency of nisoxetine on motor fibers suggests that there might be a great difference in its blocking potency on different axons types. This selective effect might be beneficial in many clinical situations (e.g. labor analgesia; early mobilization after knee or hip joint replacement).

- AA did not influence nerve conductivity, but both AEA and capsaicin caused a slight inhibition on EMG activity in high doses, but their largest applied doses were ineffective. These results suggest that the local administration of these ligands will not modify nerve activity through voltage gated ion channels. 


\section{Acknowledgement}

I would like to express my greatest gratitude to my supervisor Prof. Gyöngyi Horváth for the guidance and support over the past decade. Her altruistic work was far more than an enormous help to write my thesis and carry out my experimental work. She taught me scientific and critical thinking, what is may be the greatest tool I can use in medical practice and also in everyday life. She is not only an exceptional scholar, but also a true mentor to me.

I would like to thank the continuous help and magnanimous support for Gabriella Kékesi, who's help was essential to write my thesis and do the final stages of my work.

I also want to express my gratitude to Zita Petrowszki for her great help during the experimental phase.

I would like to thank to Gábor Tuboly the opportunity that I could join to his great work.

I want to thank the patience and tireless work for Ágnes Ábrahám-Tandari, who always helped me in countless ways.

I would like to express my gratitude to Péter Liszli for the great help in setting up the experimental protocol and devices.

My sincere thanks goes to the whole team, and specially to Prof. Gábor Jancsó and Prof. György Benedek who provided me an opportunity to join their department and gave access to the laboratory and research facilities.

I would like to express my gratitude to Margit Szikszay who introduced me to this wonderful team. She urged me to continue my scientific education, and with great wisdom, even gently pressured me to follow the right path, what was essential that time. 


\section{References}

Aidley, DJ. (1998) The physiology of excitable cells, 4th ed. Cambridge University Press, Cambridge.

Al Kury, LT, Vojtechova, OI, Yang, KH, Thayyullathil, FT, Doroshenko, P, Ramirez, AM, Shuba, YM, Galadari, S, Howarth, FC, Oz, M. (2014) Effects of the endogenous cannabinoid anandamide on voltage-dependent sodium and calcium channels in rat ventricular myocytes. Br J Pharmacol 171, 3485-3498.

Angelov, DN, Guntinas-Lichius, O, Wewetzer, K, Neiss, WF, Streppel, M. (2005) Axonal branching and recovery of coordinated muscle activity after transection of the facial nerve in adult rats. Adv Anat Embryol Cell Biol 180, 1-130.

Arancibia-Carcamo, IL, Attwell, D. (2014) The node of Ranvier in CNS pathology. Acta Neuropathol (Berl ) 128, 161-175.

Barrett, KE, Barman, SM, Boitano, S, Brooks, HL. (2016) Ganong's review of medical physiology. 25 ed. McGraw-Hill, New York City.

Bento, RF, Salomone, R, Nascimento, SB, Ferreira, RJ, Silva, CF, Costa, HJ. (2017) Mandibular branch of the facial nerve in wistar rats: new experimental model to assess facial nerve regeneration. Int Arch Otorhinolaryngol 18, 277-282.

Bernardini, N, Neuhuber, W, Reeh, PW, Sauer, SK. (2004) Morphological evidence for functional capsaicin receptor expression and calcitonin gene-related peptide exocytosis in isolated peripheral nerve axons of the mouse. Neuroscience 126, 585590.

Binshtok, AM, Bean, BP, Woolf, CJ. (2007) Inhibiton of nociceptors by TRPV1-mediated entry of impermeant sodium channel blockers. Nature 449, 607-611.

Binshtok, AM, Gerner, P, Oh, SB, Puopolo, M, Suzuki, S, Roberson, DP, Herbert, T, Wang, CF, Kim, D, Chung, G, Mitani, AA, Wang, GK, Bean, BP, Woolf, CJ. (2009) Coapplication of lidocaine and the permanently charged sodium channel blocker QX- 
314 produces a long-lasting nociceptive blockade in rodents. Anesthesiology 111, 127-137.

Bohar, Z, Toldi, J, Fulop, F, Vecsei, L. (2015) Changing the face of kynurenines and neurotoxicity: Therapeutic considerations. Int J Mol Sci 16, 9772-9793.

Boland, LM, Drzewiecki, MM. (2008) Polyunsaturated fatty acid modulation of voltage-gated ion channels. Cell Biochem Biophys 52, 59-84.

Brenneis, C, Kistner, K, Puopolo, M, Jo, S, Roberson, DP, Sisignano, M, Segal, D, Cobos, EJ, Wainger, BJ, Labocha, S, Ferreirós, N, von Hehn, C, Tran, J, Geisslinger, G, Reeh, PW, Bean, BP, Woolf, CJ. (2014) Bupivacaine-induced cellular entry of QX-314 and its contribution to differential nerve block. Br J Pharmacol 171, 438-451.

Brenneis, C, Kistner, K, Puopolo, M, Segal, D, Roberson, D, Sisignano, M, Labocha, S, Ferreiros, N, Strominger, A, Cobos, EJ, Ghasemlou, N, Geisslinger, G, Reeh, PW, Bean, BP, Woolf, CJ. (2013) Phenotyping the function of TRPV1-expressing sensory neurons by targeted axonal silencing. J Neurosci 33, 315-326.

Bucher, D, Goaillard, JM. (2011) Beyond faithful conduction: short-term dynamics, neuromodulation, and long-term regulation of spike propagation in the axon. Prog Neurobiol 94, 307-346.

Butterworth, J, Oxford, GS. (2009) Local anesthetics: a new hydrophilic pathway for the drug-receptor reaction. Anesthesiology 111, 12-14.

Butterworth, JF, Strichartz, GR. (1990) Molecular mechanisms of local anesthesia: a review. Anesthesiology 72, 711-734.

Cao, X, Cao, X, Xie, H, Yang, R, Lei, G, Li, F, Li, A, Liu, C, Liu, L. (2007) Effects of capsaicin on VGSCs in TRPV1 ${ }^{-/-}$mice. Brain Res 1163, 33-43.

Carpenedo, R, Pittaluga, A, Cozzi, A, Attucci, S, Galli, A, Raiteri, M, Moroni, F. (2001) Presynaptic kynurenate-sensitive receptors inhibit glutamate release. Eur J Neurosci $13,2141-2147$.

Catterall, WA, Cestéle, S, Yarov-Yarovoy, V, Yu, FH, Konoki, K, Scheuer, T. (2007) Voltage-gated ion channels and gating modifier toxins. Toxicon 49, 124-141. 
Catterall, WA, Swanson, TM. (2015) Structural basis for pharmacology of voltage-gated sodium and calcium channels. Mol Pharmacol 88, 141-150.

Chen, YW, Chu, CC, Chen, YC, Wang, JJ, Hung, CH, Shao, DZ. (2012) Nisoxetine produces local but not systemic analgesia against cutaneous nociveptive stimuli in the rat. Eur J Pharmacol 675, 22-25.

Chrubasik, J, Martin, E, Cousins, MJ. 1993. Advances in pain therapy II. Springer-Verlag, Berlin.

Corell, M, Wicher, G, Radomska, KJ, Daglikoca, ED, Godskesen, RE, Fredriksson, R, Benedikz, E, Magnaghi, V, Fex Svenningsen, A. (2015) GABA and its B-receptor are present at the node of Ranvier in a small population of sensory fibers, implicating a role in myelination. J Neurosci Res 93, 285-295.

Cosi, C, Mannaioni, G, Cozzi, A, Carla, V, Sili, M, Cavone, L, Maratea, D, Moroni, F. (2011) G-protein coupled receptor 35 (GPR35) activation and inflammatory pain: Studies on the antinociceptive effects of kynurenic acid and zaprinast. Neuropharmacology 60, 1227-1231.

Courtney, KR. (1975) Mechanism of frequency-dependent inhibition of sodium currents in frog myelinated nerve by the lidocaine derivative GEA. J Pharmacol Exp Ther 195, 225-236.

Cusdin, FS, Clare, JJ, Jackson, AP. (2008) Trafficking and cellular distribution of voltagegated sodium channels. Traffic 9, 17-26.

Di Marzo, V, Breivogel, CS, Tao, Q, Bridgen, DT, Razdan, RK, Zimmer, AM, Zimmer, A, Martin, BR. (2000) Levels, metabolism, and pharmacological activity of anandamide in $\mathrm{CB}_{1}$ cannabinoid receptor knockout mice. Evidence for non- $\mathrm{CB}_{1}$, non- $\mathrm{CB}_{2}$ receptormediated actions of anandamide in mouse brain. J Neurochem 75, 2434-2444.

Domoki, F, Santha, P, Bari, F, Jancso, G. (2003) Perineural capsaicin treatment attenuates reactive hyperaemia in the rat skin. Neurosci Lett 341, 127-130.

Dorfl, J. (1982) The musculature of the mystacial vibrissae of the white-mouse. J Anat 135, 147-154. 
Duan, Y, Liao, C, Jain, S, Nicholson, RA. (2008) The cannabinoid receptor agonist CP55,940 and athyl arachidonate interfere with $\left[{ }^{3} \mathrm{H}\right]$ batrachotoxinin A 20 a-benzoate binding to sodium channels and inhibit sodium channel function. Comp Biochem Physiol C Toxicol Pharmacol 148, 244-249.

Duan, Y, Zheng, J, Nicholson, RA. (2007) Vanilloid (subtype 1) receptor-modulatory drugs inhibit $\left[{ }^{3} \mathrm{H}\right]$ batrachotoxinin-A 20 -alfa-benzoate binding to $\mathrm{Na}^{+}$channels. Basic Clin Pharmacol Toxicol 100, 91-95.

Dux, M, Deak, E, Tassi, N, Santha, P, Jancso, G. (2016) Endovanilloids are potential activators of the trigeminovascular nocisensor complex. J Headache Pain 17, 53.

Elinder, F, Liin, SI. (2017) Actions and mechanisms of polyunsaturated fatty acids on voltage-gated ion channels. Front Physiol 8, 43.

Fang, YJ, Zhou, MH, Gao, XF, Gu, H, Mei, YA. (2011) Arachidonic acid modulates $\mathrm{Na}^{+}$ currents by non-metabolic pathways in rat cerebellar granule cells. Biochem $\mathrm{J} 438$, 203-215.

Frazier, DT, Narahashi, T, Yamada, M. (1970) The site of action and active form of local anethetics. II. experiments with quaternary compounds. J Pharmacol Exp Ther 171, 45-51.

Fundin, BT, Rice, FL, Pfaller, K, Arvidsson, J. (1994) The innervation of the mystacial pad in the adult-rat studied by anterograde transport of HRP conjugates. Exp Brain Res 99, 233-246.

Gamse, R, Petsche, U, Lembeck, F, Jancso, G. (1982) Capsaicin applied to peripheral nerve inhibits axoplasmic transport of substance P and somatostatin. Brain Res 239, 447462.

Ganong, AH, Lanthorn, TH, Cotman, CW. (1983) Kynurenic acid inhibits synaptic and acidic amino acid-induced responses in the rat hippocampus and spinal cord. Brain Res 273, 170-174. 
Gao, P, Bermejo, R, Zeigler, HP. (2001) Whisker deafferentation and rodent whisking patterns: behavioral evidence for a central pattern generator. J Neurosci 21, 53745380.

Gasser, HS, Erlanger, J. (1929) The role of fiber size in the establishment of a nerve block by pressure or cocaine. Am J Physiol 88, 581-591.

Gokin, AP, Philip, B, Strichartz, GR. (2001) Preferential block of small myelinated sensory and motor fibers by lidocaine - In vivo electrophysiology in the rat sciatic nerve. Anesthesiology 95, 1441-1454.

Guntinas-Lichius, O, Irintchev, A, Streppel, M, Lenzen, M, Grosheva, M, Wewetzer, K, Neiss, WF, Angelov, DN. (2005) Factors limiting motor recovery after facial nerve transection in the rat: combined structural and functional analyses. Eur J Neurosci 21, 391-402.

Hall, JE, Guyton, AC. (2016) Guyton and Hall textbook of medical physiology. 13th ed. Saunders Elsevier, Philadelphia.

Heaton, JT, Kowaleski, JM, Bermejo, R, Zeigler, HP, Ahlgren, DJ, Hadlock, TA. (2008) A system for studying facial nerve function in rats through simultaneous bilateral monitoring of eyelid and whisker movements. J Neurosci Methods 171, 197-206.

Hennings, ECP, Kiss, JP, De Oliveira, K, Toth, PT, Vizi, ES. (1999) Nicotinic acetylcholine receptor antagonistic activity of monoamine uptake blockers in rat hippocampal slices. J Neurochem 73, 1043-1050.

Henstrom, D, Hadlock, T, Lindsay, R, Knox, CJ, Malo, J, Vakharia, KT, Heaton, JT. (2012) Terminal segment surgical anatomy of the rat facial nerve: Implications for facial reanimation study. Muscle Nerve 45, 692-697.

Hilmas, C, Pereira, EF, Alkondon, M, Rassoulpour, A, Schwarcz, R, Albuquerque, EX. (2001) The brain metabolite kynurenic acid inhibits alpha7 nicotinic receptor activity and increases non-alpha7 nicotinic receptor expression: physiopathological implications. J Neurosci 12, 7463-7473. 
Hodgkin, AL, Huxley, AF. (1952) A quantitative description of membrane current and its application to conduction and excitation in nerve. J Physiol 117, 500-544.

Hohmann, MH, Kleiss, IJ, Knox, CJ, Weinber, JS, Heaton, JT, Hadlock, TA. (2014) Cable grafting permits recovery equivalent to primary repair in a rat facial nerve. JAMA Facial Plast Surg 16, 20-24.

Hong, MP, Kim, HI, Shin, YK, Lee, CS, Park, M, Song, JH. (2004) Effects of free fatty acids on sodium currents in rat dorsal root ganglion neurons. Brain Res 1008, 81-91.

Horvath, G, Kekesi, G. (2006) Interaction of endogenous ligands mediating antinociception. Brain Res Rev 52, 69-92.

Jaffe, RA, Rowe, MA. (1996) Differential nerve block. Direct measurements on individual myelinated and unmyelinated dorsal root axons. Anesthesiology 84, 1455-1464.

Jancso, G, Lawson, SN. (1990) Transganglionic degeneration of capsaicin-sensitive C-fiber primary afferent terminals. Neuroscience $39,501-511$.

Jancso, G, Such, G. (1983) Effects of capsaicin applied perineurally to the vagus nerve on cardiovascular and respiratory functions in the cat. J Physiol 341, 359-370.

Jancso, N, Jancso-Gabor, A, Szolcsanyi, J. (1968) The role of sensory nerve endings in neurogenic inflammation induced in human skin and in the eye and paw of the rat. $\mathrm{Br}$ J Pharmacol Chemother 32, 32-41.

Jiang, QX, Gonen, T. (2012) The influence of lipids on voltage-gated ion channels. Curr Opin Struct Biol 22, 529-536.

Kekesi, G, Joo, G, Csullog, E, Dobos, I, Klimscha, W, Toth, K, Benedek, G, Horvath, G. (2002) The antinociceptive effect of intrathecal kynurenic acid and its interaction with endomorphin-1 in rats. Eur J Pharmacol 445, 93-96.

Kim, HY, Kim, K, Li, HY, Chung, G, Park, CK, Kim, JS, Jung, SJ, Lee, MK, Ahn, DK, Hwang, SJ, Kang, Y, Binshtok, AM, Bean, BP, Woolf, CJ, Oh, SB. (2010) Selectively targeting pain in the trigeminal system. Pain 150, 29-40.

Kim, HI, Kim, TH, Shin, YK, Lee, CS, Park, M, Song, JH. (2005) Anandamide suppression of $\mathrm{Na}^{+}$currents in rat dorsal root ganglion neurons. Brain Res 1062, 39-47. 
Kohane, DS, Kuang, Y, Lu, NT, Langer, R, Strichartz, GR, Berde, CB. (1999) Vanilloid receptor agonists potentiate the in vivo local anesthetic activity of percutaneously injected site 1 sodium channel blockers. Anesthesiology 90, 524-534.

Krishnan, AV, Lin, CSY, Park, SB, Kiernan, MC. (2009) Axonal ion channels from bench to bedside: a translational neuroscience perspective. Prog Neurobiol 89, 288-313.

Lara-Ramírez, R, Segura-Anaya, E, Martínez-Gómez, A, Dent, MAR. (2008) Expression of interleukin-6 receptor alpha in normal and injured rat sciatic nerve. Neuroscience 152, 601-608.

Lee, GY, Shin, YK, Lee, CS, Song, JH. (2002) Effects of arachidonic acid on sodium currents in rat dorsal root ganglion neurons. Brain Res 950, 95-102.

Leung, YM, Chu, CC, Kuo, CS, Chen, YW, Wang, JJ. (2013) Nisoxetine blocks sodium currents and elicits spinal anesthesia in rats. Pharmacol Rep 65, 350-357.

Lim, TKY, MacLeod, BA, Ries, CR, Schwarz, SKW. (2007) The quaternary lidocaine derivative, QX-314, produces long-lasting local anesthesia in animal models in vivo. Anesthesiology 107, 305-311.

Liu, H, Zhang, HX, Hou, HY, Lu, XF, Wei, JQ, Wang, CG, Zhang, LC, Zeng, YM, Wu, YP, Cao, JL. (2011) Acid solution is a suitable medium for introducing QX-314 into nociceptors through TRPV1 channels to produce sensory-specific analgesic effects. Plos One 6.

Lundbaek, JA, Birn, P, Tape, SE, Toombes, GES, Sogaard, R, Koeppe II, RE, Gruner, SM, Hansen, AJ, Andersen, OS. (2005) Capsaicin regulates voltage-dependent sodium channels by altering lipid bilayer elasticity. Mol Pharmacol 68, 680-689.

Mattox, DE, Felix, H. (1987) Surgical anatomy of the rat facial nerve. Am J Otolaryngol 8, 43-47.

Mechoulam, R, Ben Shabat, S, Hanus, L, Ligumsky, M, Kaminski, NE, Schatz, AR, Gopher, A, Almog, S, Martin, BR, Compton, DR. (1995) Identification of an endogenous 2monoglyceride, present in canine gut, that binds to cannabinoid receptors. Biochem Pharmacol 50, 83-90. 
Moroni, F, Cozzi, A, Sili, M, Mannaioni, G. (2012) Kynurenic acid: a metabolite with multiple actions and multiple targets in brain and periphery. J Neural Transm 119, 133-139.

Moroni, F, Russi, P, Lombardi, G, Beni, M, Carla, V. (1988) Presence of kynurenic acid in the mammalian brain. J Neurochem 51, 177-180.

Mutoh, T, Kanamaru, A, Kojima, K, Nishimura, R, Sasaki, N, Tsubone, H. (2000) Effects of perineural capsaicin treatment on compound action potentials of superior laryngeal nerve afferents in sevoflurane-anesthetized dogs. J Vet Med Sci 62, 117-120.

Nagy, I, Santha, P, Jancso, G, Urban, L. (2004) The role of the vanilloid (capsaicin) receptor (TRPV1) in physiology and pathology. Eur J Pharmacol 500, 351-369.

Nakagawa, H, Hiura, A. (2013) Comparison of the transport of QX-314 through TRPA1, TRPM8, and TRPV1 channels. J Pain Res 6, 223-230.

Nakamura, T, Popitz-Bergez, F, Birknes, J, Strichartz, GR. (2003) The critical role of concentration for lidocaine block of peripheral nerve in vivo - Studies of function and drug uptake in the rat. Anesthesiology 99, 1189-1197.

Neishabouri, A, Faisal, AA. (2014) Saltatory conduction in unmyelinated axons: clustering of $\mathrm{Na}(+)$ channels on lipid rafts enables micro-saltatory conduction in C-fibers. Front Neuroanat 8, 109 .

Nemeth, H, Toldi, J, Vecsei, L. (2005) Role of kynurenines in the central and peripherial nervous systems. Curr Neurovasc Res 2, 249-260.

Nerbonne, JM, Kass, RS. (2005) Molecular physiology of cardiac repolarization. Physiol Rev $85,1205-1253$

Nicholson, RA, Liao, C, Zheng, J, David, LS, Coyne, L, Errington, AC, Singh, G, Lees, G. (2003) Sodium channel inhibition by anandamide and synthetic cannabimimetics in brain. Brain Res 978, 194-204.

Oszlacs, O, Jancso, G, Kis, G, Dux, M, Santha, P. (2015) Perineural capsaicin induces the uptake and transganglionic transport of choleratoxin B subunit by nociceptive C-fiber primary afferent neurons. Neuroscience 311, 243-252. 
Ozcan, G, Shenaq, S, Spira, M. (2018) Vascularized nerve tube: an experimental alternative for vascularized nerve grafts over short gaps. J Reconstruct Microsurg 9, 405-413.

Park, SB, Lin, CSY, Burke, D, Kiernan, MC. (2011) Activity-dependent conduction failure: molecular insights. J Peripher Nerv Syst 16, 159-168.

Pawlak, D, Takada, Y, Urano, T, Takada, A. (2000) Serotonergic and kynurenic pathways in rats exposed to foot shock. Brain Res Bull 52, 197-205.

Petsche, U, Fleischer, E, Lembeck, F, Handwerker, HO. (1983) The effect of capsaicin application to a peripheral nerve on impulse conduction in functionally identified afferent nerve fibres. Brain Res 265, 233-240.

Pettorossi, VE, Bortolami, R, Torre, GD, Brunetti, O. (1994) Effects of capsaicin in the motor nerve. Exp Neurol 128, 284-289.

Poliak, S, Peles, E. (2003) The local differentiation of myelinated axons at nodes of Ranvier. Nat Rev Neurosci 4, 968-980.

Porszasz, J, Jancso, N. (1959) Studies on the action potentials of sensory nerves in animals desensitized with capsaicine. Acta Physiol Acad Sci Hung 16, 299-306.

Prescott, C, Weeks, AM, Staley, KJ, Partin, KM. (2006) Kynurenic acid has dual action on AMPA receptor responses. Neurosci Lett 402, 108-112.

Raigorodsky, G, Urca, G. (1990) Spinal antinociceptive effects of excitatory amino acid antagonists: quisqualate modulates the action of N-methyl-D-aspartate. Eur J Pharmacol 182, 37-47.

Rhoades, RW, Fiore, JM, Math, MF, Jacquin, MF. (1983) Reorganization of trigeminal primary afferents following neonatal infraorbital nerve section in hamster. Dev Brain Res 7, 337-342.

Roberson, DP, Binshtok, AM, Blasl, F, Bean, BP, Woolf, CJ. (2011) Targeting of sodium channel blockers into nociceptors to produce long-duration analgesia: a systematic study and review. Br J Pharmacol 164, 48-58.

Rozsa, E, Robotka, H, Vecsei, L, Toldi, J. (2008) The Janus-face kynurenic acid. J Neural Transm 115, 1087-1091. 
Ruben, PC (Eds). (2014) Handbook of experimental pharmacology: Voltage gated sodium channels. Springer-Verlag, Berlin.

Sagie, I, Kohane, DS. (2010) Prolonged sensory-selective nerve blockade. Proc Natl Acad Sci USA $107,3740-3745$.

Salzer, JL. (2002) Nodes of Ranvier come of age. Trends Neurosci 25, 2-5.

Sann, H, Jancso, G, Rossler, W, Pierau, FK. (1995) Reduction of substance P binding sites in the spinal dorsal horn after perineural capsaicin treatment in the rat. Neurosci Lett 190, 151-154.

Santha, P, Jancso, G. (2003) Transganglionic transport of choleragenoid by capsaicinsensitive C-fibre afferents to the substantia gelatinosa of the spinal dorsal horn after peripheral nerve section. Neuroscience 116, 621-627.

Sauer, SK, Reeh, PW. (2009) Inflammation and hypersensitivity in the context of the sensory functions of axonal membranes: what are the molecular mechanisms? Dig Dis 27(S:1), $11-15$.

Schwarcz, R, Pellicciari, R. (2002) Manipulation of brain kynurenines: glial targets, neuronal effects, and clinical opportunities. J Pharmacol Exp Ther 303, 1-10.

Semba, K, Egger, MD. (1986) The facial "motor" nerve of the rat: control of vibrissal movement and examination of motor and sensory components. J Comp Neurol 247, 144-158.

Shavit, E, Beilin, O, Korczyn, AD, Sylantiev, C, Aronovich, R, Drory, VE, Gurwitz, D, Horresh, I, Bar-Shavit, R, Peles, E, Chapman, J. (2018) Thrombin receptor PAR-1 on myelin at the node of Ranvier: a new anatomy and physiology of conduction block. Brain 131, 1113-1122.

Shen, J, Fox, LE, Cheng, JG. (2012) Differential effects of peripheral versus central coadministration of QX-314 and capsaicin on neuropathic pain in rats. Anesthesiology $117,365-380$.

Sisk, AL. (1992) Long-acting local anesthetics in dentistry. Anesth Prog 39, 53-60. 
Starmer, CF, Yeh, JZ, Tanguy, J. (1986) A quantitative description of QX222 blockade of sodium channels in squid axons. Biophys J 49, 913-920.

Stone, TW. (1993) Neuropharmacology of quinolinic and kynurenic acids. Pharmacol Rev 45, 309-379.

Stone, TW. (2000) Development and therapeutic potential of kynurenic acid and kynurenine derivatives for neuroprotection. Trends Pharmacol Sci 21, 149-154.

Strichartz, GR. (1973) The inhibition of sodium currents in myelinated nerve by quaternary derivatives of lidocaine. J Gen Physiol 62, 37-57.

Strichartz, GR (Eds). (1987) Handbook of experimental pharmacology: Local anesthetics. Springer-Verlag, Berlin, Heidelberg.

Strichartz, GR, Sanchez, V, Arthur, GR, Chafetz, R, Martin, D. (1990) Fundamental properties of local anesthetics. II. measured octanol: buffer partition coefficients and pKa values of clinically used drugs. Anesth Analg 71, 158-170.

Sugimoto, K, Murakawa, Y, Zhang, W, Xu, G, Sima, AAF. (2000) Insulin receptor in rat peripheral nerve: its localization and alternatively spliced isoforms. Diabetes Metab Res Rev 16, 354-363.

Szalardy, L, Klivenyi, P, Zadori, D, Fulop, F, Toldi, J, Vecsei, L. (2012) Mitochondrial disturbances, tryptophan metabolites and neurodegeneration: medicinal chemistry aspects. Curr Med Chem 19, 1899-1920.

Szallasi, A. (1994) The vanilloid (capsaicin) receptor: receptor types and species differences. Gen Pharmacol 25, 223-243.

Szigeti, C, Santha, P, Kortvely, E, Nyari, T, Deak, E, Horvath, VJ, Dux, M, Gulya, K, Jancso, G. (2012) Disparate changes in the expression of transient receptor potential vanilloid type 1 receptor mRNA and protein in dorsal root ganglion neurons following local capsaicin treatment of the sciatic nerve in the rat. Neuroscience 201, 320-330.

Taheri, S, Cogswell, LP, Gent, A, Strichartz, GR. (2003) Hydrophobic and ionic factors in the binding of local anesthetics to the major variant of human alpha1-acid glycoprotein. $\mathbf{J}$ Pharmacol Exp Ther 304, 71-80. 
Tominaga, M, Caterina, MJ, Malmberg, AB, Rosen, TA, Gilbert, H, Skinner, K, Raumann, BE, Basbaum, AI, Julius, D. (1998) The cloned capsaicin receptor integrates multiple pain-producing stimuli. Neuron 21, 531-543.

Turski, WA, Schwarcz, R. (1988) On the disposition of intrahippocampally injected kynurenic acid in the rat. Exp Brain Res 71, 563-567.

Urbanska, EM, Chmielewski, M, Kocki, T, Turski, WA. (2000) Formation of endogenous glutamatergic receptors antagonist kynurenic acid - differences between cortical and spinal cord slices. Brain Res 878, 210-212.

Vecsei, L, Beal, MF. (1991) Comparative behavioral and pharmacological studies with centrally administered kynurenine and kynurenic acid in rats. Eur J Pharmacol 196, 239-246.

Vecsei, L, Szalardy, L, Fulop, F, Toldi, J. (2013) Kynurenines in the CNS: recent advances and new questions. Nat Rev Drug Discov 12, 64-82.

Verberne, AJM, Widdop, RE, Maccarrone, C, Jarrott, B, Beart, PM, Louis, WJ. (1990) Intrathecal kynurenate reduces arterial pressure, heart rate and baroreceptor-heart rate reflex in conscious rats. Neurosci Lett 114, 309-315.

Wang, JH, Simonavicius, N, Wu, XS, Swaminath, G, Reagan, J, Tian, H, Ling, L. (2006) Kynurenic acid as a ligand for orphan $\mathrm{G}$ protein-coupled receptor GPR35. J Biol Chem 281, 22021-22028.

Wang, SY, Mitchell, J, Wang, GK. (2007) Preferential block of inactivation-deficient $\mathrm{Na}^{+}$ currents by capsaicin reveals a non-TRPV1 receptor within the $\mathrm{Na}^{+}$channel. Pain 127 , 73-83.

Wang, XC, Wang, S, Zhang, M, Gao, F, Yin, C, Li, H, Zhang, Y, Hu, SJ, Duan, JH. (2015) Alpha-Dendrotoxin-sensitive Kv1 channels contribute to conduction failure of polymodal nociceptive C-fibers from rat coccygeal nerve. J Neurophysiol 115, 947957.

Weiss, L, Silver, J, Weiss, J. (2004) Easy EMG. A guide to performing nerve conduction studies and electromyography. 6th ed. Butterworth-Heinemann, Edinburgh. 
Weller, K, Reeh, PW, Sauer, SK. (2011) TRPV1, TRPA1, and CB1 in the isolated vagus nerve - Axonal chemosensitivity and control of neuropeptide release. Neuropeptides $45,391-400$.

Yaksh, TL. (1989) Behavioral and autonomic correlates of the tactile evoked allodynia produced by spinal glycine inhibition: effects of modulatory receptor systems and excitatory amino acid antagonists. Pain 37, 111-123.

Yamamoto, T, Yaksh, TL. (1992) Spinal pharmacology of thermal hyperesthesia induced by constriction injury of sciatic nerve. Excitatory amino acid antagonists. Pain 49, 121 128.

Yamanaka, K, Kigoshi, S, Muramatsu, I. (1984) Conduction-block induced by capsaicin in crayfish giant axon. Brain Res 300, 113-119.

Yi, Z, Nagao, M, Bossev, DP. (2012) Effect of charged lidocaine on static and dynamic properties of model bio-membranes. Biophys Chem 160, 20-27.

Yokogawa, F, Kiuchi, Y, Ishikaw, Y, Otsuka, N, Masuda, Y, Oguchi, K, Hosoyamada, A. (2002) An investigation of monoamine receptors involved in antinociceptive effects of antidepressants. Anesth Analg 95, 163-168.

Yunoki, T, Takimoto, K, Kita, K, Funahashi, Y, Takahashi, R, Matsuyoshi, H, Naito, S, Yoshimura, N. (2014) Differential contribution of Kv4-containing channels to A-type, voltage-gated potassium currents in somatic and visceral dorsal root ganglion neurons. J Neurophysiol 112, 2492-2504.

Zagorodnyuk, VP, Chen, BN, Costa, M, Brookes, SJH. (2002) 4-aminopyridine- and dendrotoxin-sensitive potassium channels influence excitability of vagal mechanosensitive endings in guinea-pig oesophagus. Br J Pharmacol 137, 1195-1206.

Zhang, YQ, Ji, GC, Wu, GC, Zhao, ZQ. (2003) Kynurenic acid enhances electroacupuncture analgesia in normal and carrageenan-injected rats. Brain Res 966, 300-307. 